\author{
P A U L R E M Y
}

\title{
Manejo de crisis
}

\section{¿Qué hacer el día en que todo está en contra nuestra?}

\author{
Segunda edición
}

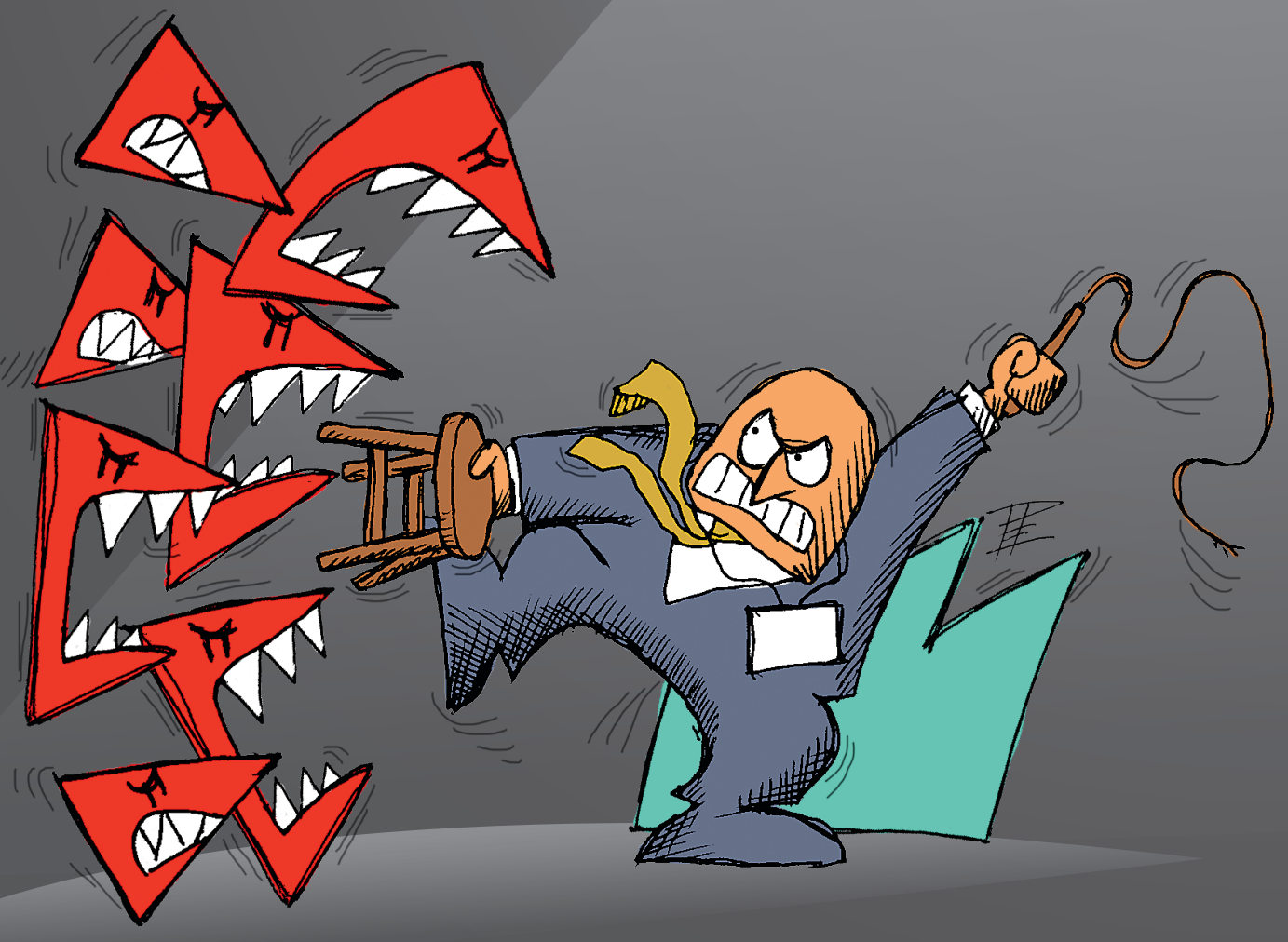


P A U L R E Y

Manejo de crisis

¿Qué hacer el día en que todo está en contra nuestra?

Segunda edición

Lima, noviembre de 2015

Universidad Peruana de Ciencias Aplicadas 
(C) Universidad Peruana de Ciencias Aplicadas (UPC)

Primera publicación: julio de 2011

Edición:

Diana Félix

Corrección de estilo:

Luigi Battistolo

Diseño de cubierta:

Christian Castañeda

Ilustración:

Pepe Sanmartín

Diagramación:

Diana Patrón Miñán

Editor del proyecto editorial

Universidad Peruana de Ciencias Aplicadas S. A.C.

Av. Alonso de Molina 1611, Lima 33 (Perú)

Teléf: 313-3333

www.upc.edu.pe

Primera edición: julio de 2011

Segunda edición: noviembre de 2015

Versión ebook 2015

Digitalizado y Distribuido por Saxo.com Perú S.A.C.

www.saxo.com/es

yopublico.saxo.com

Telf: 51-1-221-9998

Dirección: Av. 2 de Mayo 534 Of. 304, Miraflores

Lima-Perú

\section{Universidad Peruana de Ciencias Aplicadas (UPC) \\ Centro de información}

Remy, Paul. Manejo de crisis. ¿Qué hacer el día en que todo está en contra nuestra?

Lima: Universidad Peruana de Ciencias Aplicadas (UPC), 2015

ISBN de la versión impresa: 978-612-318-040-9

ISBN de la versión epub y mobi: $\mathrm{xxxx}$

ISBN de la versión pdf: $\mathrm{xxxx}$

ADMINISTRACIÓN DE LA CRISIS, SOLUCIÓN DE CONFLICTOS, ADMINISTRACION DEL RIESGO

658.4056 REMY

Todos los derechos reservados. Esta publicación no puede ser reproducida, ni en todo ni en parte, ni registrada en o transmitida por un sistema de recuperación de información, en ninguna forma ni por ningún medio, sea mecánico, fotoquímico, electrónico, magnético, electroóptico, por fotocopia o cualquier otro, sin el permiso previo, por escrito, de la editorial.

El contenido de este libro es responsabilidad de los autores y no refleja necesariamente la opinión de los editores. 
A Susana, mi esposa, por su ejemplo de amor, y a Gonzalo Galdos, por su ejemplo de liderazgo 


\section{Contenido}

Prólogo

$\begin{array}{lr}\text { Introducción a la primera edición } & 13\end{array}$

Introducción a la segunda edición

Capítulo 1. Naturaleza

Entender las crisis

Enfrentar las crisis

Capítulo 2. Manejo

¡Tenemos una crisis! ¿Qué hacemos?

Los objetivos

Equipamiento previo necesario

Comité de crisis

Niveles de activación

Centro de control

Lista de contactos relevantes

Preguntas sobre los hechos

Formato del plan de contención

Secuencia de acción ante una crisis

¿Cómo vender la necesidad de un plan de manejo de crisis a su equipo? 
Las comunicaciones pueden contener o expandir las crisis 133

$\begin{array}{ll}\text { Entender a los medios de comunicación } & 134\end{array}$

$\begin{array}{ll}\text { ¿Qué comunicar? } & 137\end{array}$

$\begin{array}{ll}\text { La pirámide comunicacional } & 146\end{array}$

$\begin{array}{ll}\text { Comunicaciones en corporaciones internacionales } & 147\end{array}$

$\begin{array}{ll}\text { Voceros } & 148\end{array}$

$\begin{array}{lc}\text { Capítulo 4. Precrisis } & 153\end{array}$

$\begin{array}{lc}\text { Se puede hacer mucho antes de una crisis } & 153\end{array}$

$\begin{array}{ll}\text { Gestión de riesgos } & 154\end{array}$

Metodología para la gestión de riesgos 156

$\begin{array}{ll}\text { Consideraciones adicionales } & 170\end{array}$

$\begin{array}{ll}\text { Dos técnicas más } & 171\end{array}$

$\begin{array}{lr}\text { Capítulo 5. Poscrisis } & 173\end{array}$

$\begin{array}{ll}\text { La crisis no acaba con la crisis } & 173\end{array}$

$\begin{array}{ll}\text { Recuperación } & 174\end{array}$

$\begin{array}{ll}\text { Aprendizaje } & 176\end{array}$

$\begin{array}{ll}\text { Autoevaluación } & 179\end{array}$

Expectativas ciudadanas por un lado, desempeño real por el otro 180

Capítulo 6. Reputación y extramercado 183

$\begin{array}{ll}\text { Reputación, imagen y riesgos } & 183\end{array}$

Ser y parecer, no ser y parecer, no parecer y ser 186

$\begin{array}{ll}\text { Tres mitos sobre la reputación } & 187\end{array}$ 
Vulnerabilidad en el extramercado

Activistas como competidores

Manejo de rabia versus manejo de información

La sociedad escéptica

El arte de la persuasión

La doble vía de la reputación y la crisis

Capítulo 7. Responsabilidad social

Las ambigüedades naturales

La responsabilidad social más importante

La exigibilidad de la responsabilidad social

La evaluación

Avatar

212

El responsable interno

Retos y dificultades de proyectos sociales

Responsabilidad social en las entidades estatales

¿Cómo vamos en el Perú en responsabilidad social?

El estándar ISO 26000

ISO 26000 no certificable

Capítulo 8. Conflictos sociales

Proyectos de inversión privada y relacionamiento social armónico

La crisis como fase particular dentro de un conflicto

De resfrío a pulmonía

Trabajando sobre los factores internos procrisis 
Equipos de prevención social y respuesta inmediata

Transparencia

Una entrevista sobre conflictos sociales

Final

Crisis como oportunidad

Anexo

Tablero estratégico de manejo de crisis

Bibliografía 


\section{Prólogo}

Parafraseando una expresión que proviene del campo de los seguros contra riesgos, podríamos decir que es preferible tener un plan de manejo de crisis y no necesitarlo que necesitarlo y no tenerlo. No se me ocurre mejor carta de presentación para el libro que este concepto y la trayectoria profesional del autor en los últimos veinte años. En ella, con su venia, quiero dejar en segundo plano logros académicos, institucionales y empresariales para referirme, en forma prolija, a su labor casi evangelizadora en la generación de conciencia acerca de la naturaleza, el origen y la gestión de crisis; labor que tuvo como marco un país que durante muchos años no conoció otra realidad que las crisis y que, sin embargo, era incapaz de interiorizar su esencia y de entender que no solo se pueden anticipar porque son consecuencia de nuestras acciones o inacciones, sino que también se pueden manejar una vez que surgen.

Conocí al autor, Paul Remy, hace ya 16 años, cuando lo recluté como ejecutivo principal y responsable de la recién fundada autoridad ambiental del país, el Consejo Nacional del Ambiente (Conam), y me di cuenta desde el primer instante de que me encontraba frente a un profesional atípico, mucho más interesado en la causa en la que nos comprometíamos y su trascendencia que en las competencias y recursos necesarios para acometer la gesta. Al mismo tiempo, muy poco le inquietaba el marcado giro profesional que le propuse, de modo tan alegre como entusiasta, a su promisoria carrera como abogado. Convencido de la legitimidad y pertinencia de la visión propuesta, Paul demostró, en cada etapa posterior, que nunca más podría ocupar un asiento en la tribuna de los que esperan que las cosas pasen. Su actitud y temperamento siempre lo situaron en el centro de la acción, usando la palabra y el conocimiento como herramientas para adscribir escépticos en la épica tarea de construir mejores instituciones, mejores empresas y un mejor gobierno.

Cuando leí este libro con detenimiento, entendí que tiene algo de autobiográfico, porque su vida ha tenido capítulos literalmente similares a los descritos en ejemplos empresariales. Doy fe de que detrás de toda reconfortante recomendación presente en este libro existe una experiencia propia acuñada por su convicción de asesor, labrada 
con la misma intensidad con la que el agua moldea la roca, presionándola sin violencia, rodeándola con justeza y delineando una nueva forma que elimina la fricción.

No se puede hablar de manejo de crisis desde una base teórica, por ello es mayor la autoridad de los contenidos vertidos en este libro cuando su autor ha enfrentado crisis ambientales y disonancias políticas de primer orden, cuando ha trabajado articulando la empresa con la comunidad y cuando ha sobrellevado y emergido exitosamente tanto de valerosas como de difíciles pruebas.

Como estudioso del proceso de toma de decisiones, encuentro lecciones fundamentales para la gestión de situaciones a contracorriente de reacciones intuitivas o instintivas. La mente humana fue evolucionando para asegurar nuestra supervivencia, y no la calma deliberada que a veces se requiere al enfrentar una crisis. Paul nos ilustra en forma muy didáctica acerca de cuándo correr y cuándo pensar, pero lo más importante es que tiene la habilidad de enseñarnos a pensar mientras corremos...

Gonzalo Galdos

Vicepresidente académico de Laureate Perú 


\section{Introducción a la primera edición}

Las crisis son eventos destructivos. De un momento a otro, todo cambia, se altera, se pone en contra. Los márgenes financieros de la empresa se ven amenazados, así como su posición en el mercado, su reputación, la moral de los empleados, la lealtad de los clientes, el flujo de suministros de los proveedores... Hasta la propia continuidad del negocio está en juego. Todo se agrava momento a momento; hora a hora, el daño escala con agresividad y se expande. La crisis pareciera tener vida propia. Hechos o factores, incluso desconectados, son absorbidos por su campo gravitacional y contribuyen a complicar la situación más aún. En momentos se convierte en el centro de atención de los medios de comunicación, sometido al juicio crítico de la opinión pública, la comunidad y los inversionistas. Múltiples voces claman sanciones, represalias, boicots, devoluciones, reparaciones, indemnizaciones, despidos, retiro de productos, suspensión o cese de operación, disculpas públicas, garantías, cambios regulatorios, etcétera. También piden cabezas.

No hay tiempo que perder. Es necesario convocar al equipo de toma de decisiones, acopiar información para entender qué está ocurriendo realmente, priorizar las acciones, repartir las tareas, verificar que se ejecuten, vigilar la evolución de los hechos, convocar a los medios, comunicar los hechos a la opinión pública, tranquilizar a los empleados, informar a los inversionistas, controlar a los que exageran las noticias. Todo, en medio de decenas de llamadas telefónicas de todo tipo, cobertura negativa de prensa y mil problemas más. La inacción será un acelerador de la crisis. Quizá no se disponga de más de dos horas para abordar todas esas tareas. Lo que haga en ellas determinará la evolución de la crisis en los próximos días, semanas o años. Una crisis no manejada a tiempo puede expandir su impacto negativo y extenderlo a una situación de debilitamiento continuo y permanente, y ni qué decir de una crisis mal manejada. Si se sale vivo de ella, lo cual puede ser incluso un mérito, a veces nunca se cierran las cicatrices que deja.

¿Qué tan preparada está su empresa para conducirse en una turbulencia de este calibre? ¿Le suena familiar la frase «comité de crisis»? ¿Cuál es su nivel de alerta para anticiparse a situaciones adversas de rápida ignición o prepararse para enfrentarlas? 
¿Ha sentido más de una vez estar cerca de ellas y por suerte el problema no se produjo? ¿Tiene una hoja de ruta clara para enfrentar crisis? ¿Podrá su equipo gerencial dominar la tensión, el miedo, la ira, la miopía, la angustia, la incertidumbre? ¿Actuará como un grupo cohesionado o los intereses individuales dirigirán las actitudes? ¿Su propio ego le jugará a favor o en contra? En fin, si toma una foto de su empresa, ¿qué es lo que ve?

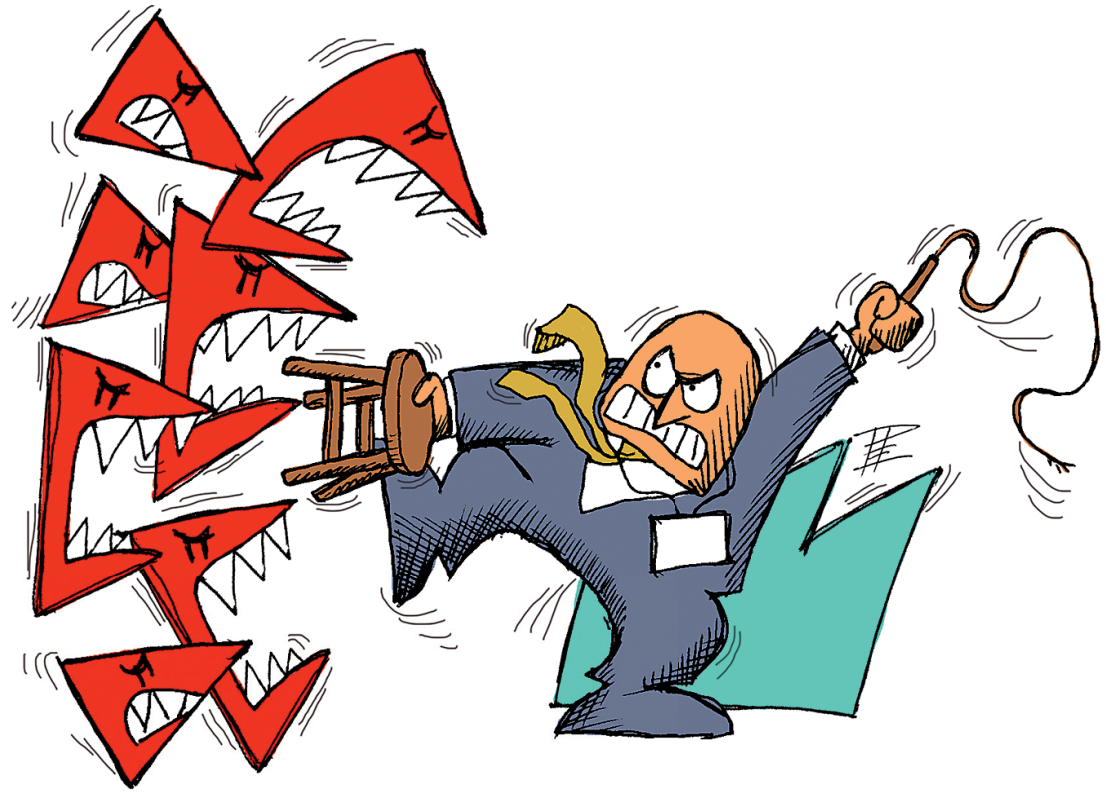

Este libro busca ayudarlo a construir sus propias capacidades para enfrentar las crisis. Digo propias, pues nadie más que usted —lamentablemente no es una tarea tercerizable - será el artífice de que su empresa sobreviva y hasta crezca a partir de la caída, o de que se convierta en un buen insumo para la autopsia y de aprendizaje para los demás. Conociendo qué hay detrás de todas y cada una de las crisis y de su compleja naturaleza, con el manejo de algunas herramientas clave para contenerlas en su fase expansiva y el entrenamiento para actuar bajo fuego cruzado, saldrá bastante mejor librado. Es más, hasta podrá sortearlas oportunamente. Así, usted y el equipo gerencial que lo acompaña en su empresa podrán anticiparse a estos eventos destructivos y estar preparados, orientar coherentemente sus acciones y comunicaciones y contener rápidamente el daño, para así ingresar en la fase de recuperación eficaz y aprendizaje. Las empresas preparadas para manejar las crisis limitan hasta en un tercio el impacto previsible y se recuperan aproximadamente en la mitad del tiempo que les toma a las que no cuentan con esta preparación. 
Dado que todos somos vulnerables a las crisis, el contenido del libro es pertinente para todo tipo de organizaciones, sin importar su tamaño, objeto, giro, naturaleza privada o pública, o si tiene o no fines de lucro. Se aplica por igual a empresas, gremios, asociaciones y organismos estatales, así como a entidades educativas, ONG, congregaciones religiosas, partidos políticos, clubes, etcétera. Por lo tanto, el término «empresa» usado a lo largo del libro cubre a toda clase de organizaciones por igual, y en muchos aspectos funciona también para las familias y las personas. Más de una vez he debido releerlo y exigirme coherencia a mí mismo, coherencia entre lo que escribo y lo que hago en mi vida personal.

El libro se compone de seis capítulos. El primero analiza las crisis y los conceptos clave que involucran, sus fases, la dinámica de impacto y de control, la correlación entre eventos e impactos y la contención del daño. El segundo capítulo aborda directamente el manejo de las crisis, señala los objetivos prioritarios y cómo prepararse para enfrentarlas: comités de crisis, responsabilidades de sus integrantes, criterios de activación, formatos de planes de contención, etcétera.

El tercer capítulo refiere el tema de comunicaciones; saber qué y cómo comunicar, así como privilegiar pocos mensajes clave que se repitan constantemente (al contrario de la creencia de que es mejor desplegar muchos mensajes) y recomendaciones a los voceros para las entrevistas. El cuarto capítulo trata sobre cómo trabajar las situaciones previas a las crisis; es decir, el campo de la anticipación y la gestión de riesgos. En rigor, debería haber colocado primero este capítulo y después el de manejo de crisis, pero las personas somos más proclives a interesarnos en la prevención tras pasar por un problema (después de robado, candado), de modo que opté por desarrollar primero la gestión del problema y luego cómo prepararse antes de que surja.

El quinto capítulo trata de la poscrisis; es decir, la etapa residual en que, lejos de olvidar la crisis sufrida, hay aún muchas cosas que hacer, fundamentalmente la recuperación, el aprendizaje y la autoevaluación. Las crisis enseñan, y no siempre se aprovecha ese valor. Caer por segunda vez en una misma crisis es una señal inequívoca de que no se aprendió de la primera. Para terminar, el capítulo seis reflexiona desde el título de «¿Arquetipos?» sobre un conjunto de temas asociados a las crisis, como el liderazgo, la reputación, la imagen, el extramercado, la relación con las ONG, la responsabilidad social, los proyectos sociales, el Estado, las oportunidades y otros.

Debo agradecer de corazón a los que me han brindado su valioso apoyo: a Claudia Doig, quien me dio una temprana y útil retroalimentación con respecto a mis primeras notas; a Carla Castellanos, quien también de manera desinteresada y con tanta genero- 
sidad como profesionalismo revisó íntegramente el estilo de redacción del libro, vigiló la consistencia de sus contenidos, detectó y resolvió incoherencias, desafió varias de mis aseveraciones y ofreció ingeniosas salidas a mis frecuentes entrampamientos, todo con una especial combinación de rigor y entusiasmo; y a Pepe Sanmartín, diseñador capaz de comunicar lo complejo, interpretándolo artística y amenamente, de manera simple en una expresiva ilustración.

No puedo dejar de reconocer a la Escuela de Posgrado de la UPC, que me dio la oportunidad de dictar el curso que en mucho inspira este libro. Allí mis alumnos inadvertidamente son mis auténticos profesores, contribuyendo poderosamente en cada discusión, simulación e interacción en clase a mi propia comprensión del tema, seguramente mucho más de lo que yo puedo hacerlo con ellos. Finalmente, agradezco al Fondo Editorial de la UPC, que acogió con fe este trabajo y permitió hacerlo realidad.

Espero sinceramente que este sencillo libro, escrito con más entusiasmo que lucidez, lo ayude a entender las crisis de manera distinta, a anticiparse a ellas y a evitarlas, y, si no hay escapatoria, a enfrentar su turbulencia guiando el timón con decisión y acierto.

Paul Remy 


\section{Introducción a la segunda edición}

Esta obra se publicó por primera vez en el año 2011. Esta segunda edición no viene corregida (aunque seguramente debiera) pero sí significativamente aumentada.

A través de mi ejercicio profesional había venido perfeccionando e integrando algunas herramientas de creación propia con otras desarrolladas por expertos en la materia. Dichas herramientas se exponían en la primera edición. Incluían un formato de una sola página pensado en servir de plantilla por un comité de crisis en plena turbulencia. Aparecían entonces el formato de matriz de objetivos a proteger y objetivos a sacrificar, así como el de estrategia de contención, que permite visualizar el enfoque central de la estrategia y la asignación de muchos recursos y energía a pocos objetivos. Estos dos eran de creación propia. A ellos agregaba un formato de comunicaciones y mensajes clave, que es una adaptación de la propuesta de Hal Hart.

En esta segunda edición incorporo dos formatos más. En primer lugar, el menú de opciones de estrategias de contención, que refleja más de 10 años de dedicación profesional en manejo de crisis y ofrece todo un listado de alternativas para que, solas o combinadas, pueda elegirse la que mejor convenga para contener una crisis. Están catalogadas en estilo conciliador, agresivo o medio.

El otro formato lo constituye el denominado «radar de confianza» (radar trust) de Daniel Diermeier, quien fuera mi profesor de Manejo de Crisis en Kellogg School of Management, Northwestern University, y que apareció publicado en su libro del año 2011. Esta interesante herramienta permite conciliar la dimensión racional con la emocional que caracteriza a los seres humanos. Para comprenderla estoy dedicando un acápite especial a esta distinción entre cerebro racional y emocional, que es clave para definir las estrategias de contención de crisis.

Lo relevante es que en una crisis, en plena turbulencia, con información confusa, absoluta incertidumbre, riesgo de escalada y a pocas horas de una intensa exposición mediática, el equipo a cargo deberá muy rápidamente identificar la naturaleza del problema, tomar las primeras acciones de contención y capturar en el público la sensación de que su organización — aun en plena crisis- es consecuente con su prédica 
de valores y preocupación por los demás. Dentro de todo ello, su activo más crítico, la reputación, estará en su momento más delicado. ¿Cómo protegerlo?

Las cinco herramientas, cada una plasmada en un formato de una página, están diseñadas para que quien tenga una crisis al frente pueda llenarlas por sí mismo. Para facilitar su uso, se visualizan todas juntas en un anexo al final del libro, bajo la denominación de «Tablero estratégico de manejo de crisis».

Todo ello aparece como una nueva incorporación del primer capítulo del libro, sobre naturaleza de crisis. Otra novedad es la incorporación de un acápite sobre la elección de alternativas, con una metodología cuantitativa que puede destrabar un proceso de toma de decisiones ante opciones que influyen de manera diversa sobre los múltiples intereses de la empresa ante una crisis. Finalmente, otro aspecto nuevo importante es la distinción en algunas situaciones complejas que más tienen que ver con el manejo de la rabia y la indignación de los grupos de interés, que con el manejo de la información.

Los capítulos dos, tres, cuatro y cinco, sobre manejo de crisis, comunicaciones, precrisis y poscrisis, respectivamente, no han tenido mayores variaciones. Quien tuvo ocasión de leer mi primer libro encontrará muchos contenidos nuevos en el primer capítulo, que son los que he mencionado, pero no tantos en el segundo ni en el tercero..., aunque una segunda lectura no viene mal. Pero sí hay muchas novedades en los tres capítulos últimos.

Había venido desarrollado una serie de contenidos en materia de reputación, responsabilidad social y conflictividad socioambiental que someramente había abordado en mi libro de 2011 bajo el capítulo de «Arquetipos». Sentía ahora que eran material suficiente para un libro nuevo. Sin embargo, visto en perspectiva, estos constituían la continuación de las materias tratadas en mi primer libro, y mis editores del Fondo Editorial, gentil y pertinentemente, me sugirieron que incorporara ese nuevo material en una segunda edición del primero.

Estos nuevos contenidos se plasman en nuevos capítulos: el sexto sobre reputación y extramercado, el sétimo de responsabilidad social y el octavo sobre conflictividad social.

La reputación era clave abordarla, pues constituye el activo más valioso de cualquier organización, y a la vez el más vulnerable en eventos de crisis. Manejo de crisis es fundamentalmente protección de la reputación; por eso estamos tan dispuestos a sacrificar lo que sea con tal de no vernos vapuleados ante la opinión pública. Y, como señala Philip Kotler, los equipos están más dedicados a defender la reputación que a 
construirla. Dicho de otra manera, la reputación es como la salud. Nos preocupamos de ella solo cuando estamos enfermos. De manera que convenía tratar la reputación también desde el lado de construcción de la misma, no solo de su protección. Sinceramente, creo que los marketeros han evolucionado enormemente en las últimas décadas (¡alguien hasta diría que demasiado!), pero no tanto así los expertos en reputación. No obstante, hay desarrollos muy interesantes que intento incorporar al libro.

Reputación conecta además directamente con responsabilidad social, que está en el capítulo sétimo, donde comparto algunas ideas sobre cómo entender la responsabilidad social y cómo evitar los sesgos que deforman el concepto, cómo facilitar su implementación, cómo identificar riesgos tempranamente; en fin, enfoques sencillos más basados en el sentido común que en elaboradas fórmulas y metodologías que no siempre nos acercan a la real naturaleza de las cosas. Y, dentro de ese marco, hago referencia al estándar ISO 26000, el referente global más relevante sobre responsabilidad social, y en cuyo proceso tuve el privilegio de colaborar conduciendo el comité establecido por el Indecopi para ese fin.

La combinación de protección de la reputación en situaciones de crisis y responsabilidad puede sonar extraña. Pero, insisto, por un instante piense cuál es su principal objetivo al enfrentar una crisis. Sin duda, proteger valor: marca, posición en el mercado, rentabilidad, reputación, calidad de la relación con sus stakeholders. Pero, cuando en tiempos de paz diseña sus estrategias de responsabilidad social, ¿cuál es su propósito? Crear valor... en los mismos aspectos. Al final del día, la combinación no es forzada. Más bien fluye simple y clara: proteger valor en tiempos turbulentos es manejo de crisis, crear valor en tiempos de paz en buena medida es responsabilidad social.

Sin duda, la reputación es fundamentalmente lo que los demás (no nosotros mismos) están diciendo de nosotros, lo que evidentemente tiene que ver con cómo la organización se vincula con los demás. El modo de relacionamiento con grupos de interés (como colaboradores, proveedores, clientes, autoridades, el entorno social y ambiental) define entonces la reputación. No lo hace la memoria institucional ni los reportes de sostenibilidad, que en realidad expresan un contenido, pero no crean el contenido.

Finalmente, el capítulo octavo trata sobre el complejo tema de la conflictividad social asociada a proyectos de inversión privada. No es sencillo determinar si la oposición viene de un reclamo legítimo por parte de la comunidad o proviene de un movimiento político antiinversión organizado, o de una combinación de ambos. Sea cual fuere, es imprescindible una clara identificación del problema, apartándose de los ses- 
gos de apreciación, y distinguir entre lo visible y lo subyacente, además de la capacidad de prever y evitar una disrupción costosa, o al menos contener su daño.

Debo reiterar mi agradecimiento a quienes me acompañaron en la primera edición del libro. Su aporte sigue totalmente vigente. Pero para esta segunda edición quiero subrayar mi agradecimiento al equipo del Fondo Editorial de la UPC. Siempre abiertos a ideas, permeables a la innovación y rigurosos donde deben serlo.

Espero que este libro sea visto como un sencillo aporte útil a quienes por curiosidad, interés o necesidad perciban que la turbulencia será una condición de operación permanente en las sociedades modernas y que, lejos de lamentarse, hay mucho que se puede hacer para llegar a puerto seguro.

Paul Remy 
«Si pudieses encarar el triunfo y el desastre, y tratar de la misma manera a estos dos impostores...».

Rudyard Kipling 


\section{Capítulo 1. Naturaleza}

\section{ENTENDER LAS CRISIS}

\section{Todos hemos pasado por ellas}

No existe persona que no haya afrontado un proceso de crisis, ya sea como protagonista, testigo, víctima o artífice. Hay quien ha aprendido de ellas y ha evitado nuevas caídas, pero también hay quien ha vuelto a tropezar con las mismas circunstancias. Con las empresas ocurre exactamente lo mismo. Se ven envueltas en las crisis, sienten sus efectos dañinos, pero se recuperan, no desaparecen en el intento, y aprenden. Para cada persona o empresa la crisis es única, aunque, viendo las diversas experiencias de crisis, es posible descubrir factores comunes y modos en que se pueden prever, para protegerse de ellas.

Nadie está libre de una crisis. A diario somos testigos

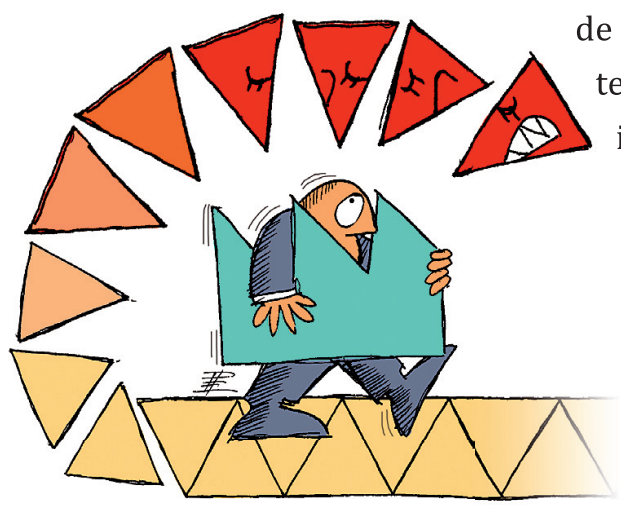
como los medios de comunicación transmiten acusaciones de conductas abiertamente inaceptables por la sociedad —más allá de si estas son fundamentadas o no-, que clama por sanciones y amenaza con pavorosas demandas legales, o con dejar de adquirir los productos de quien aparece en falta. Así, la pregunta correcta que debemos plantearnos no es si nuestra empresa pasará por un proceso de crisis o no, sino cómo se presentará esta y cuándo. 
Nada puede poner más a prueba la consistencia de una empresa que el modo como esta responde a una crisis. No solo someterá a una presión sin precedentes los procesos de toma de decisiones, el alineamiento interno y los esquemas de cooperación entre áreas, sino que enfrentará su reputación y credibilidad a una auténtica prueba ácida. Es más, las crisis muestran de qué madera están hechas realmente las organizaciones. De esta manera revelan su rostro real.

Así como las empresas, las personas y las familias también pasan por crisis, lo mismo ocurre con los países y las comunidades cuando están frente a desastres naturales, cambios ambientales, colapsos económicos o desórdenes políticos o sociales. La delincuencia y la falta de seguridad ciudadana ocasionan crisis de diferentes escalas en las sociedades, de la misma forma que lo harían un terremoto, inundaciones o cualquier tipo de epidemia. El colapso del sistema financiero internacional originado en 2008 fue una crisis, al igual que determinados eventos políticos que ocurren permanentemente en el mundo. Muchas crisis tienen autores intencionales, como los que desarrollan sabotajes, ataques cibernéticos y terrorismo global. Todas estas crisis comparten características comunes, sin importar su escala, complejidad o dinámica.

\section{¿Cuándo estamos en crisis?}

Con frecuencia decimos que estamos en crisis, ya sea como una frase coloquial o con una sensación de certeza. Puede haber mucha subjetividad: alguien podría calificar una situación negativa determinada como un problema serio, mientras que otra persona podría afirmar que es una crisis.

Para entendernos, podemos coincidir en que las crisis son circunstancias que amenazan la vida o la salud del negocio: quieren liquidarlo o dejarlo gravemente afectado, de forma que su futuro previsible difícilmente será el mismo. Algo así como la categoría superior o premium de los problemas.

Cuando escuchamos la palabra «crisis», tendemos a relacionar este término con eventos como los siguientes:

- Responsabilidad en muertes o heridos en gran escala.

- Daño severo al patrimonio público o privado.

- Contaminación de gran magnitud.

- Protestas de vecinos en escala creciente. 
- Presión de grupos de interés (stakeholders) por hechos negativos.

- Procedimientos judiciales o administrativos de gran trascendencia.

- Empleados que se quejan amarga y públicamente.

- Cobertura mediática negativa persistente.

- Hostilidad sistemática de políticos.

\section{Tres etiquetas}

Las etiquetas son el calificativo genérico que la opinión pública atribuye a quien está en plena crisis en sus primeras horas. Se adhieren con fuerza y la gente se guía por ellas sin importar si son bien merecidas o no. No hay una infinidad de etiquetas, no hay una combinación de ellas. Solo hay tres y solo se recibe una a la vez: en una crisis, se dirá que uno es un villano, una víctima o un héroe.

La etiqueta de «villano» es la que se asigna con más frecuencia. Si causó daños, todas las protestas, denuncias y rechazos de los consumidores, así como las investigaciones y sanciones de los reguladores y autoridades, buscarán que compense por el mal hecho e incluso que deje de operar. Es posible ser doblemente villano en caso de reincidencia visible, y, ante esa circunstancia, las eventuales excusas resultan por lo general muy débiles. Se puede ser hasta un triple villano, cuando se opera como villano silencioso desde hace buen tiempo sin que nadie lo haya sospechado, pues ha ocultado intencionalmente información o ha engañado a la sociedad. Existen conductas ocultas que, una vez hechas públicas, matan. Se puede incluso ser más villano aun: cuando inicialmente se niega la culpa y luego hay que admitirla, cuando la evidencia no puede ocultarse más. De hecho, los dilemas de ser transparente y hacer públicas las responsabilidades (el llamado disclosure) son los más difíciles de resolver.

\section{Chocolatero villano}

El director ejecutivo de una de las marcas más conocidas y de mayores ventas de chocolates en el Reino Unido es informado de que se han detectado algunas trazas de salmonela en sus productos. Los niveles son bajos, al parecer no son potencialmente dañinos para la salud humana, aunque el jefe de sanidad de la planta (siempre exagerado en opinión del director ejecutivo) insiste en que el 
único nivel aceptable de salmonela en un chocolate es cero. Se decide no sacrificar el lote ni retirarlo de los puntos de distribución al público en aras de no causar alarmas, erosionar la marca innecesariamente y perder la producción. Poco después, la verdad sale a la luz. El argumento de que los niveles de contaminación del producto son muy bajos y por consiguiente inocuos no convence a nadie; la palabra «salmonela», por sí sola, combinada con un producto orientado principalmente a consumidores jóvenes y niños, causa un desastre mediático y operativo. Las consecuencias son graves: cierre temporal de once plantas, pérdidas de treinta millones de libras esterlinas por retiro de productos, un millón de libras esterlinas en penalidades y veinte millones en mejoras sanitarias. El daño a la marca y a su reputación es incalculable.

La segunda forma de ser etiquetado en una crisis es como víctima. Ocurre cuando las circunstancias colocan a la empresa como entidad pasiva de las consecuencias de hechos de otros o de la naturaleza, como en el caso de un desastre natural o de un sabotaje. Pero cuidado: la sociedad es rigurosa para conceder este calificativo y escruta de modo detallado si efectivamente hay una causalidad entre el hecho externo y los impactos negativos. Lo hace, además, desde diferentes estándares. Jugar esa carta requiere de convicción y certeza con respecto al detalle de las circunstancias que motivaron el evento. Una sospecha de que no se fue del todo víctima, sino que determinadas acciones u omisiones contribuyeron al daño, le hará ganar la etiqueta de villano. Otro factor es que la etiqueta debe provenir espontáneamente de la opinión pública; exigirla explícitamente - aunque corresponda- desnaturaliza el mérito. En otras palabras, debe venir sola.

Por último, se es etiquetado como héroe cuando, en las circunstancias de una crisis que la empresa no ha originado, esta asume una actitud decidida en favor del interés de los demás, y asume riesgos propios y sacrifica valor justamente en protección de la comunidad. Si el evento fue trascendente, el efecto positivo en la reputación estará vigente durante muchos años. Evidentemente, el hecho adverso no puede ser causado por la empresa. Si esta hace un esfuerzo extremo para paliar un problema que ella misma ha motivado, esa minimización del daño puede reducir el tamaño de la etiqueta de villano, pero no reemplazarla por la de héroe. Ser héroe es una etiqueta muy especial, pocas veces otorgada aunque muy positiva para la empresa. 


\section{Farmacéutica heroína}

Un caso emblemático es el del popular analgésico Tylenol de Johnson \& Johnson. En 1985, un psicópata desconocido en Chicago reemplazó el contenido de las cápsulas de Tylenol por cianuro. Ocurrió solo en algunas tiendas. Quince personas fallecieron con muy pocos días de diferencia. Cuando la Policía comprobó que todas ellas habían sido envenenadas y que además habían consumido Tylenol, Johnson \& Johnson, lejos de escudarse en un «no es nuestra culpa y que la Policía identifique al asesino», puso la seguridad de las personas en primer lugar. Paralizó toda su producción de Tylenol (su producto estrella), retiró todos sus lotes de producto y lideró una campaña nacional en todos los medios de prensa que llegó hasta el pueblo más pequeño, para que el producto no se consumiera. Una campaña de antimarketing suicida en aras de proteger a las personas.

Cuando reintrodujeron el producto (que se daba ya por liquidado), innovaron en la seguridad de los frascos mediante la cobertura de platina de invulnerabilidad (que hoy se ve en todos los frascos de medicamentos, lo que significa que transformaron la industria) y diseñaron una cápsula expandible (que, una vez separada, no puede volver a unirse; otra adaptación imitada por la industria). El modo en que el consumidor estadounidense premió esa actitud de Johnson \& Johnson hizo que hasta hoy se le siga considerando entre las marcas más confiables. En un sector como el farmacéutico, en el que la eficacia del medicamento depende mucho de cuánto el paciente realmente «cree» en esa pastilla (los placebos lo demuestran), ese atributo imprime toda la diferencia.

\section{Fases de las crisis}

Cada crisis muestra tres etapas claramente identificables: una de ignición, cuando empieza a mostrar sus síntomas y a desplegar su impacto; otra de expansión, que llega a un clímax que causa el mayor daño, y la etapa de declinación, cuando la crisis amaina. Estas fases describen una curva que puede tener sus variantes, pero, al final, gráficamente son una curva, así sean gripes, colapsos financieros, epidemias, desastres naturales o líos familiares. Estos patrones claramente marcados están presentes en todas las crisis, que pueden representarse así: 


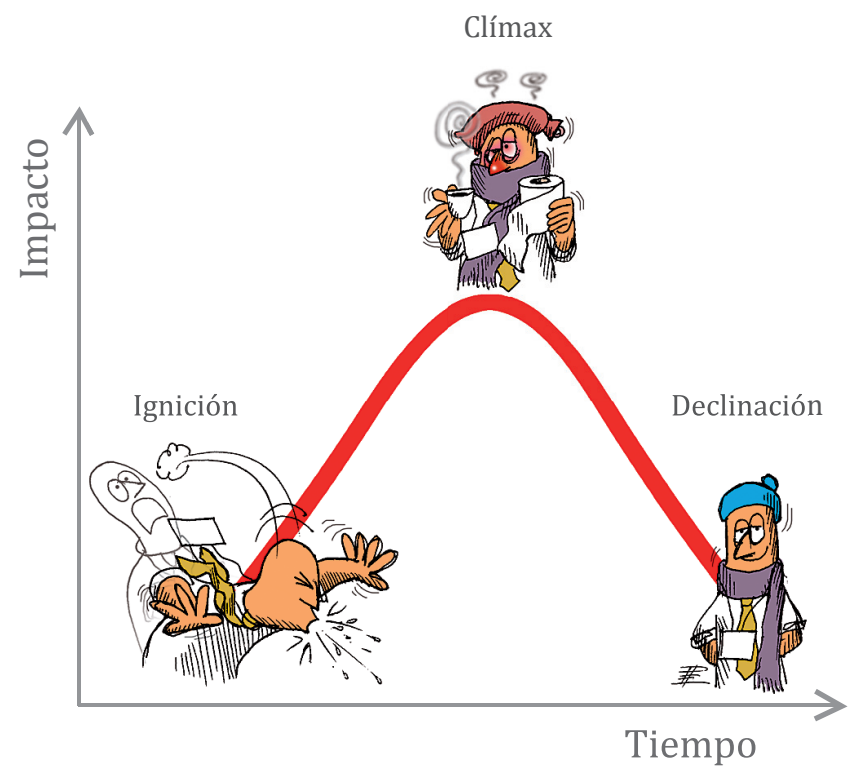

Si la crisis es de muy rápido desarrollo, se verá así:

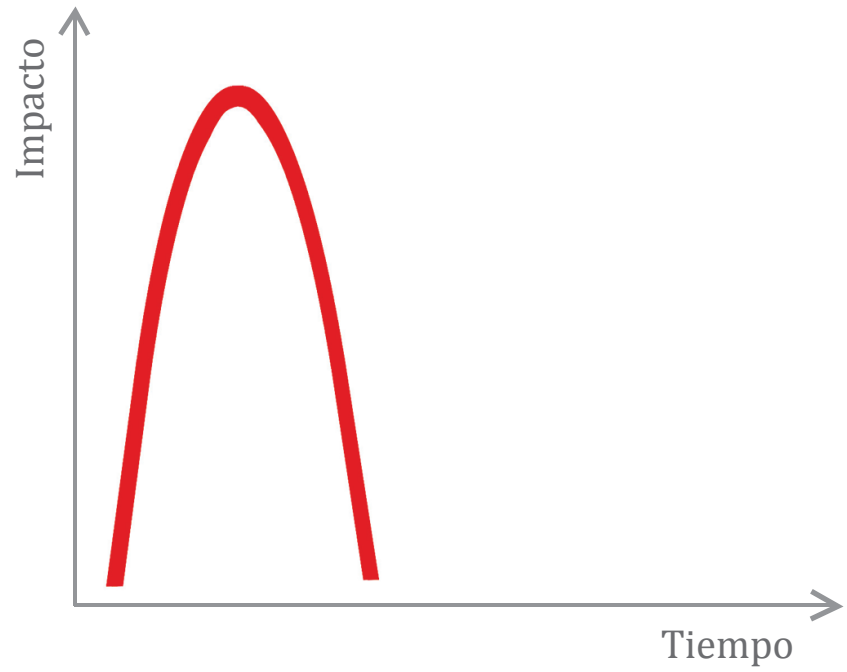

Si es una crisis de larga duración, que no tiende a bajar, como una dolencia crónica, se muestra como una meseta. 


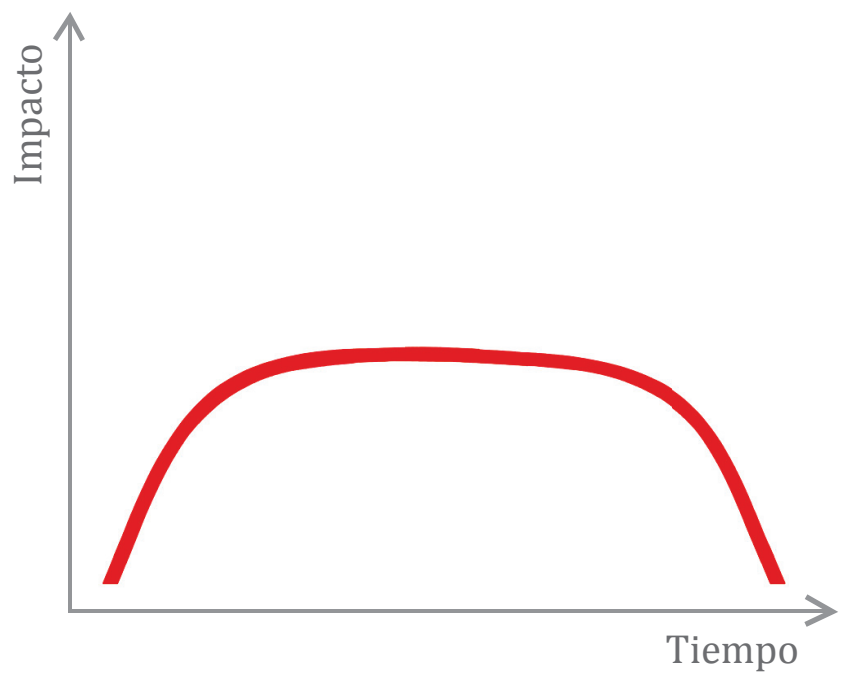

En otros casos, uno se encuentra en una ida y venida de crisis más o menos recurrentes, de episodios repetitivos, con ciertas diferencias de impactos de los que no se puede salir. Incluso puede tratarse de eventos secuenciados sin conexión causal.

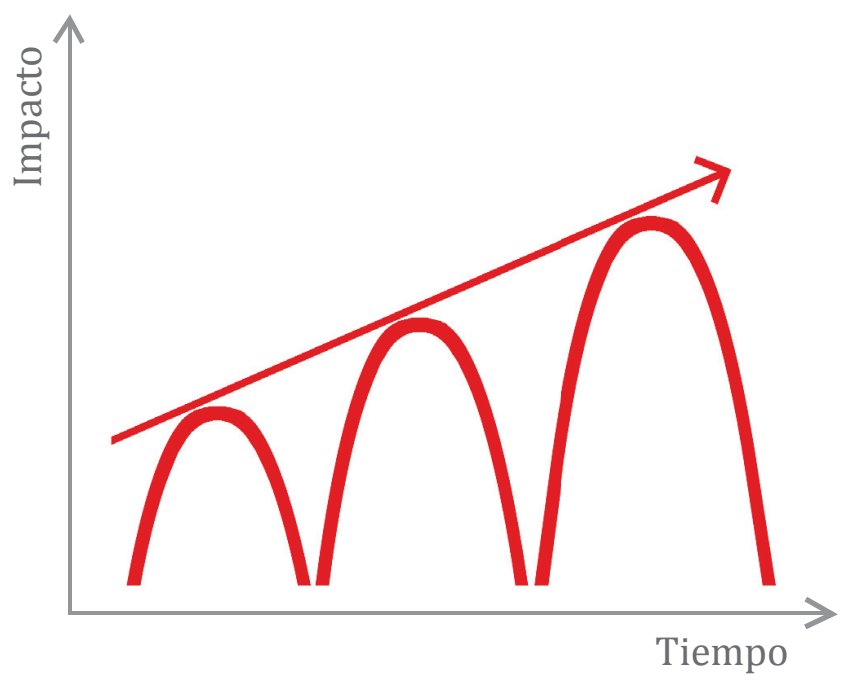




\section{De una crisis a otra en un minuto}

Imagínese que va caminando por la calle con un traje nuevo, carísimo. Usted luce formidable. De pronto empieza a llover torrencialmente y se empapa. Su reacción inmediata es proteger su traje nuevo. Necesita encontrar un refugio, y rápido. Ve la puerta de un edificio abierta, y en cuanto empieza a entrar en él, un malgeniado perro le bloquea la entrada y, además, amenaza con morderle. Su prioridad de proteger su traje desaparece inmediatamente, y es reemplazada con evitar ser mordido, mientras retrocede hacia la lluvia. Después de todo, es preferible mojarse un poco más que quedarse sin traje y sin pierna. Pero en su intento precipitado por retirarse, choca, sin darse cuenta, con una dama que también venía apresurada y buscaba un lugar donde refugiarse. Ahora parece enfrentar una nueva crisis, ya que la mujer yace en el piso, al parecer inconsciente, y mientras intenta reanimarla (en medio de inmensos charcos de agua), una irónica sonrisa se esboza en sus labios al recordar que hace unos instantes estaba preocupado por tratar de mantener seco su traje nuevo. Ahora sus pensamientos se llenan de alivio al ver que la dama se recupera, y usted agradece que su brusco golpe no la haya matado. Ella se sienta, pero en vez de celebrar su ayuda, mira alrededor y lo coge de las solapas de su alguna vez hermoso traje. Grita: «iMi bebé!, ¿dónde está mi bebé?». Usted voltea la mirada y advierte, entre cláxones y neumáticos chirriantes, un solitario cochecito que baja por el centro de una concurrida intersección.

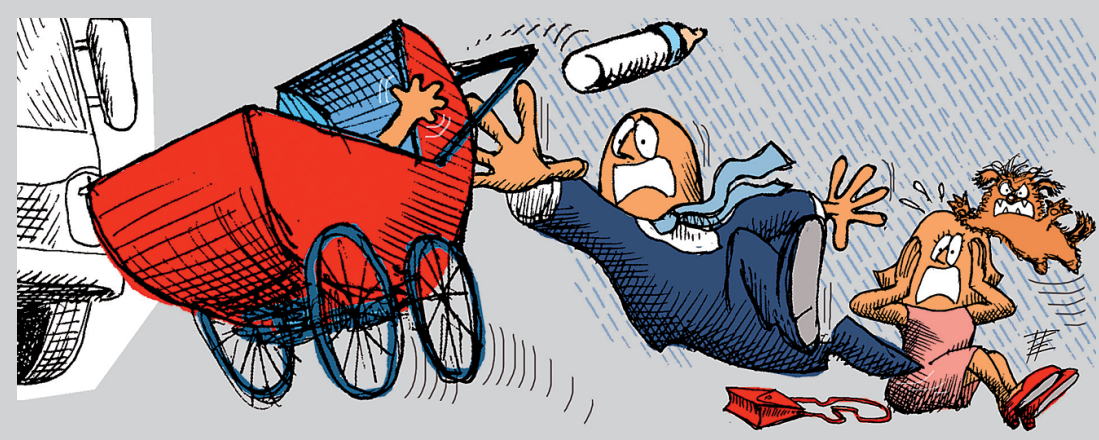


En esos pocos instantes, usted ha sido bombardeado por una serie de crisis a las que espero que nunca se enfrente. Durante ese tiempo, ciertas cuestiones urgentes requirieron su atención inmediata hasta que otros asuntos más urgentes suplantaron, rápidamente, las preocupaciones anteriores. Finalmente, ocurrió algo que ya no puede empeorar más. Olvide la lluvia, olvide el traje, olvide el perro, olvide a la mujer. ¡Pero levántese y corra con todas sus fuerzas para salvar al bebé! Ese bebé es el punto máximo de la crisis ${ }^{1}$.

También hay crisis simultáneas de diversa intensidad, o crisis de corto plazo que se juntan con crisis de largo plazo:

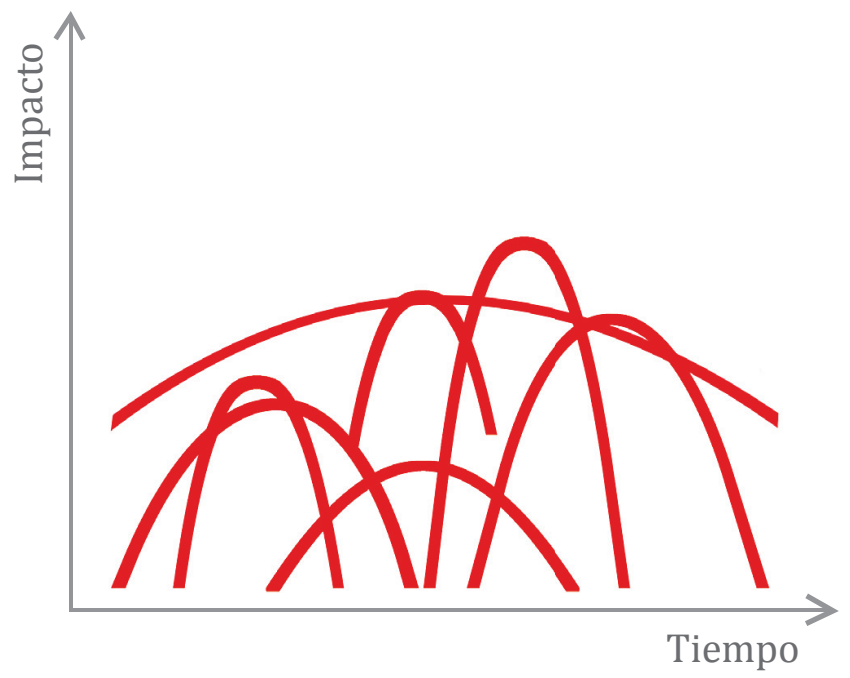

Es posible advertir incluso situaciones en que la crisis no ha entrado en ignición, pero, como la bomba de tiempo ya está programada, nadie la podrá detener. No da señales; ni siquiera un tictac revela su presencia. Solo es cuestión de tiempo. Muchas veces la fase silente tiene años de gestación. Cuando esta es extensa, algunos la denominan «ruido continuo de baja intensidad». 


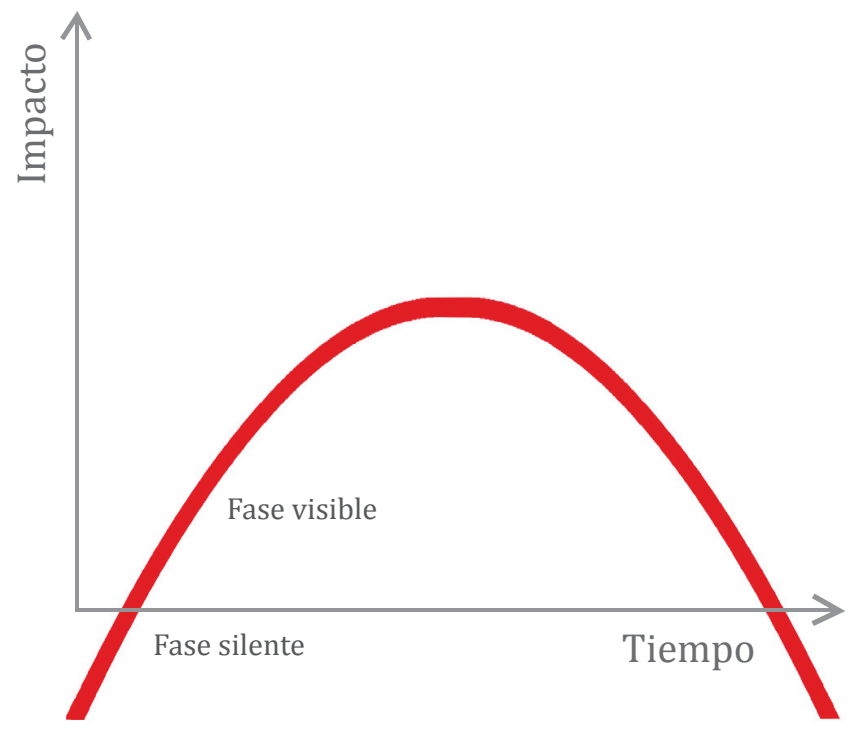

\section{La presión alta}

¿Recuerda el término con el que se alude a la presión arterial alta? Es el asesino silencioso. No tiene síntomas. La persona se siente perfectamente. Un mal día tiene un inusual y fuerte dolor de cabeza, mareo, y, minutos después, el infarto al cerebro. Lamentablemente, esta persona tenía hipertensión hacía tiempo, seguro años, pero estaba oculta. Su dolencia era asintomática, no daba señales. Esta circunstancia ocultaba su peligro. Cuando percibió los primeros síntomas ya era tarde, pues el colapso vino inmediatamente después. Justamente, la tarea del médico es explorar los síntomas ocultos, sumergirse debajo de la línea de síntomas visibles y detectar, mediante una serie de exámenes especializados, las dolencias de este tipo. El drama de la presión alta es que estos exámenes preventivos son muy sencillos, tan sencillos como tomarse la presión arterial periódicamente y visitar al médico. A pesar de ello, la indiferencia nos hace convivir con el asesino silencioso de manera inadvertida. 


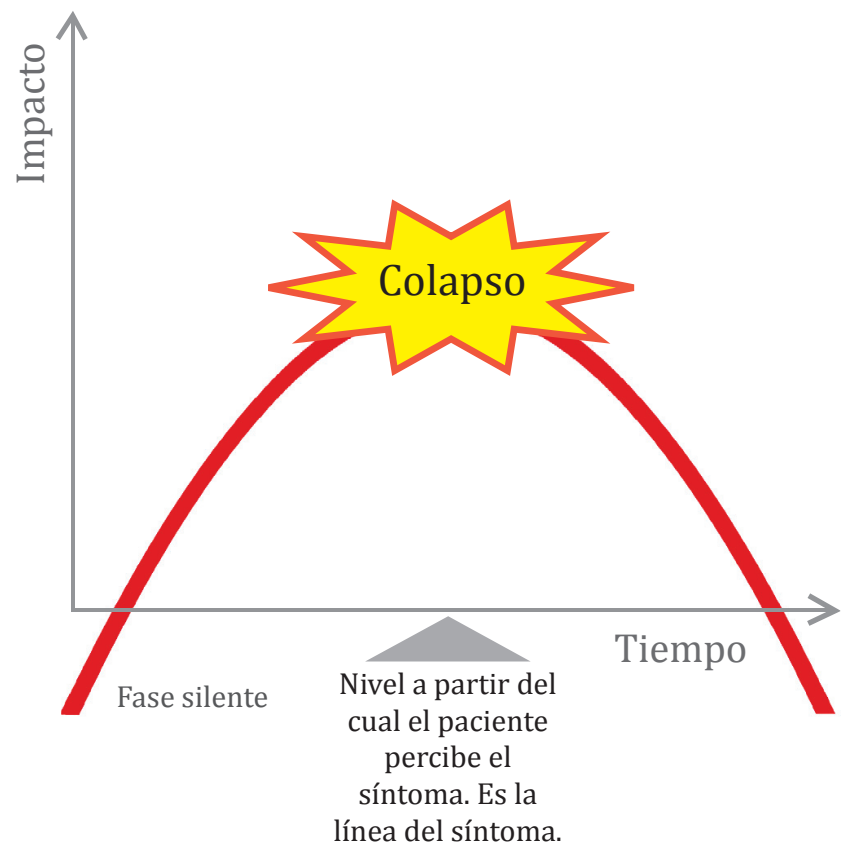

Muchas empresas tienen la línea del síntoma muy alta. Los problemas están, pero nadie avisa, nadie se siente responsable, no parece tan grave. Si el jefe no ve problemas, entonces no los hay. En fin, mil modos de cubrirlos. Cualquier análisis poscrisis evidencia la presencia de este patrón. Todos creemos en lo que queremos creer. Si nuestro deseo es no tener problemas, creeremos ilusamente que no los tenemos. Lamentablemente, será la realidad la que nos hará ver que estábamos equivocados. 


\section{Ventanas de intervención}

A cada fase de la crisis le corresponde una acción diferente, aunque las líneas divisorias no siempre están claramente marcadas. Por ello, saber conscientemente en qué etapa está cada crisis es vital para abordarla de modo adecuado.

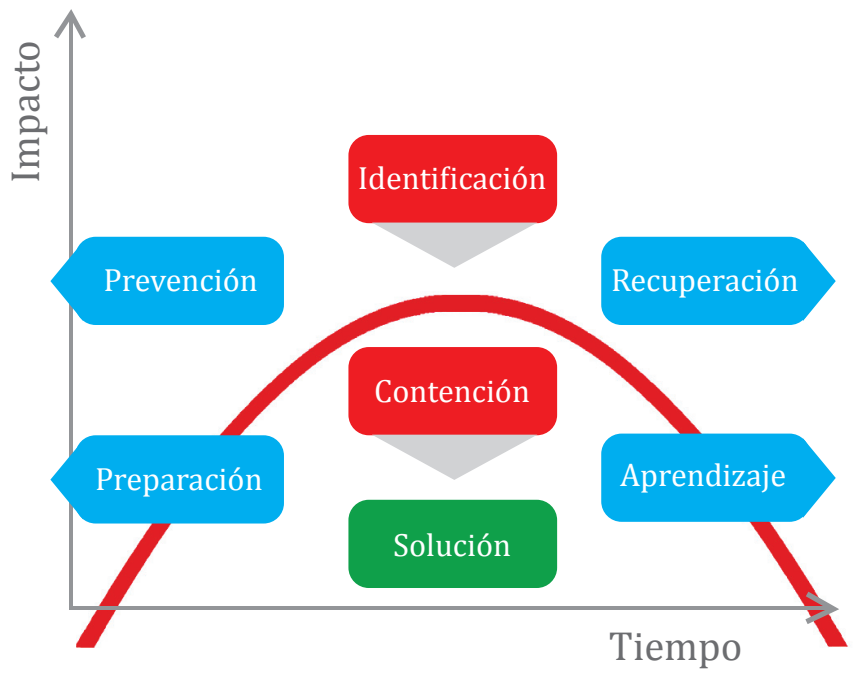

Fuente: Diermeier 2011.

Prevención. Es la identificación temprana de los riesgos que podrían generar una crisis y que, debida y oportunamente abordados, pueden ser evitados.

Preparación. Es la adaptación anticipada a un evento negativo cuya ocurrencia no puede evitarse. La prevención y la preparación se integran desde el concepto de gestión de riesgos.

Identificación. Es el reconocimiento de las características que presenta una crisis que acaba de estallar. Plantea múltiples planos dinámicos y simultáneos que se necesita comprender.

Contención. Es la acción concreta y de rápido despliegue orientada a evitar la expansión del impacto de la crisis o su escalada. 
Solución. Es la medida orientada a neutralizar la causa de la crisis de manera parcial, temporal o total. Busca fundamentalmente evitar la reedición del problema, actuando sobre su raíz, resolviéndolo de fondo y compensando los daños.

Recuperación. Es el esfuerzo de retomar la posición que se tenía antes de la crisis en diversos ámbitos: operativo, logístico, financiero, de reputación, laboral y legal, entre otros.

Aprendizaje. Es el análisis de las circunstancias que determinaron la crisis, la eficacia de la respuesta y el desempeño de la empresa a lo largo del evento. Es decir, la evaluación del desempeño antes, durante y después de la crisis.

Prevención y preparación corresponden al estado de precrisis; identificación, contención y solución, a la etapa de crisis en sí; y recuperación y aprendizaje, a la fase de poscrisis.

\section{Submarinos de guerra}

Toda la secuencia de una crisis puede verse y analizarse metafóricamente desde la perspectiva de un submarino de guerra. Su misión es simple: atacar sin ser visto. Su riesgo está en que, una vez detectado, es muy vulnerable. Las dramáticas películas de cine de la Segunda Guerra Mundial no reflejan las terribles vivencias que esas tripulaciones soportaron. De 40000 tripulantes de la Alemania nazi que se embarcaron en ellos, solo regresaron 12000.

Cualquier capitán de submarino sabía perfectamente en qué condiciones podía ser detectado: visualmente cuando estaba en superficie, o mediante el sonido cuando estaba sumergido. Para prevenir ser ubicado, reducía al mínimo los tiempos en superficie y navegaba de noche, lejos de los convoyes enemigos. Sumergido, a la menor señal de presencia enemiga se detenía, apagaba motores, incluso se disponía un silencio total a bordo. Nadie hablaba: los sensores de los barcos eran capaces de escuchar hasta conversaciones dentro del submarino.

Pero si eran detectados, se lanzaba una orden inmediata de prepararse: ataque con torpedos a la nave, evasión, rápida inmersión a la franja de termo- 
clina (zona de diferencias térmicas para camuflar la nave del sonar) o al suelo marino si la profundidad lo permitía, tripulación a sus zonas de comando o de protección. Luego se empezaba a recibir el ataque de cargas de profundidad. Pocas experiencias humanas podrían ser más terribles: pavorosas explosiones, sacudidas, crujidos y gritos en ambientes confinados, por momentos a oscuras; ruidos de entradas de agua, con mamparas y planchas de metal que cedían a la presión exterior. Podían ser 15 minutos o tres horas. El objetivo de la nave agresora era no irse hasta asegurar la destrucción total del submarino, para lo cual no caían en el engaño de maniobras de simulación de daños de su víctima, como dejar escapar combustible o aceite del motor.

Apenas cesaba el ataque, el capitán del submarino necesitaba identificar el nivel de daño sufrido, debía saber qué había sucedido, por lo que solicitaba un rápido informe de daños. Le comunicaban varios aspectos: periscopio averiado, tubos lanzatorpedos inutilizables, lastres secundarios inoperativos, bombas de succión destruidas, entrada masiva de agua a los compartimientos 1 y 2 que amenazaba al 3, motor principal operativo al $40 \%$, motor secundario operativo al 50 \% y muchos datos más. De toda esa información, el capitán debía seleccionar qué demandaba contención inmediata; debía identificar el daño inminente que podría llevar a la nave de dañada a perdida, y con ella a su tripulación, con él incluido.

De todo ese informe de daños, detectaba uno que por sus características era el más importante: la entrada de agua que amenazaba al compartimiento 3 . Todo lo demás podía esperar, pues si bien eran daños importantes, ninguno tenía el potencial de agravar el problema en ese momento. El compartimiento 3 sí, pues sabía que con tres compartimientos inundados no era posible recuperar la flota- 
bilidad. Era fundamental impedir que el compartimiento 3 reciba más agua, era indispensable sellarlo. Salvando ese compartimiento, se podría salvar el submarino. El capitán estaba combinando un dato reciente (compartimiento 3 amenazado de agua) con una información que ya tenía (los submarinos se hunden con tres compartimientos anegados).

La contención de la crisis lo obligaba a dar una orden: cerrar el compartimiento 3 de inmediato. Todos los esfuerzos debían orientarse a esa acción. Daba la orden, pero se le indicaba que no sería posible llevarla a cabo, pues había seis tripulantes heridos en su interior, y tomaría algo de diez minutos sacarlos de allí. Diez minutos..., demasiado tiempo. El compartimiento se iba a inundar totalmente en mucho menos. El dilema del capitán era terrible: ¿esperar ese tiempo para salvar a seis tripulantes y arriesgar la nave entera, u ordenar cerrar con ellos dentro, sacrificar a seis hombres y salvar a sesenta? Todos los pensamientos y sentimientos se agolpaban en su mente y corazón. ¿Qué esperaban de él su tripulación, sus mandos o su familia? No tenía tiempo. Debía optar por lo que su posición le demandase: cerrar el compartimiento. Quizá tenga que amenazar con su arma al oficial a quien le encargó cumplir la orden si este se resistiese a obedecerlo. Su orden se cumple y se hace lo que se debe hacer, lo que su posición le exige, aun cuando no pueda dormir en paz nunca más en su vida y los sentimientos de culpa (no merecida) lo atormenten por el resto de sus días.

Si se contiene la entrada de agua, la tripulación del submarino dedicará todo su tiempo y energía a solucionar y restaurar lo que pueda por sus propios medios. El submarino continuará su misión si recupera su operatividad o regresará a puerto para reparaciones mayores. Le colocarán nuevos equipos, reemplazarán lo que esté averiado; incluso lo potenciarán para fortalecer sus estructuras o hacerlo más rápido. Recuperarán su capacidad operativa para que vuelva a emprender su misión.

Finalmente, el alto mando naval le pedirá al capitán que informe sobre lo que pasó antes, durante y después del ataque. Cómo fue detectado el submarino, qué maniobras de evasión funcionaron y cuáles no, cómo se preparó para el ataque, qué procedimientos funcionaron y cuáles deberían cambiarse, cómo respondió la nave, cómo reaccionó la tripulación, cómo tomó la decisión de cerrar el compartimiento 3, cuán prestamente fue ejecutada su orden, cómo organizó 
el reflotamiento, cómo mantuvo la moral de su tripulación. Todo con el objeto de aprender de esa experiencia y de ser más eficaces en futuras misiones.

Antes de que se retire de esa reunión, le piden un minuto: la evaluación de su caso a posteriori indica que, en realidad, la decisión de cerrar el compartimiento 3 fue apresurada; el tiempo de inundación habría tomado 30 minutos, de modo que no habría sido necesario sacrificar a esos seis tripulantes: había tiempo de sobra para sacarlos. Le precisan que es una investigación confidencial, solo para efectos de aprendizaje y mejora continua, que no habrá ninguna consecuencia de responsabilidad legal, que su rango y hoja de servicios quedarán limpios, de modo que puede ir tranquilo.

El capitán abandona la reunión devastado y siente que el alma abandona su cuerpo.

\section{Escalada: pasando de una crisis grave a otra peor}

Existe algo particular en la naturaleza de las crisis: una vez que aparecen, buscan complicarse, profundizarse y extenderse. Se puede pasar de un nivel de crisis a otro superior rápidamente. Están codificadas para agravarse, ahondar su daño e incluso hacer sinergia con hechos no conectados y amplificar su impacto negativo. Si nada la detiene, la gripe se convertirá en pulmonía. Es más, el punto de clímax de una crisis, lejos de decaer, puede convertirse en el punto de partida de una crisis superior ${ }^{2}$. Las crisis también escalan horizontalmente en la empresa. El problema, que empezó como asociado al área de producción, en horas (como las bombas de racimo) involucra a finanzas, logística y ventas. Incluso puede ir más allá de una suma de daños por áreas y afectar el valor total de la empresa o su reputación. se producirán disrupciones en aspectos internos y externos en muchísimos flancos. Las crisis son procesos dinámicos y caóticos, no son discretas ni están marcadas en una secuencia de tiempo lineal. Pueden incubarse, estallar, extender su fuego, reducir su intensidad, extenderse de nuevo incluso con más energía. El ámbito de una crisis puede expandirse y articularse a temas conectados o desconectados, dependiendo de estos y de cómo llaman la atención en diferentes momentos, a medida que dicha crisis se despliega y abre un mayor contexto en el entorno social en el que ocurre (Cfr. Boin y Hart 1996: 545). 


\section{La onda expansiva}

En el caso de un incendio en las instalaciones de una empresa industrial, la compañía de seguros cubrirá los daños según las pólizas correspondientes (si las tiene y la empresa está debidamente cubierta); incluso el lucro cesante por el tiempo que deje de operar. Aparentemente, la crisis producto del incendio ha sido superada, pero esto no es necesariamente así.

La ola expansiva viene después: los vecinos que vivieron de cerca el incendio no quieren, en circunstancia alguna, que la fábrica vuelva a operar en el mismo lugar, y están decididos a imponer su decisión. Por otro lado, los clientes no pudieron esperar los meses necesarios para que la fábrica retome su operatividad y restablezca el suministro al que estaban acostumbrados. Es más, a los pocos días del incendio, cerraron contratos con otros proveedores que vieron en el incendio su propia oportunidad. En el hecho de que no se pueda reconstruir la fábrica y de que los clientes se hayan ido con la competencia, la ola expansiva del incendio muestra su real impacto.

La crisis pasó a ser un problema distinto y más grave. Si los esfuerzos de persuadir a los vecinos no prosperan (además, la municipalidad no se arriesgará a dar licencias cuando su vecindario está en pie de guerra. Dicho de otro

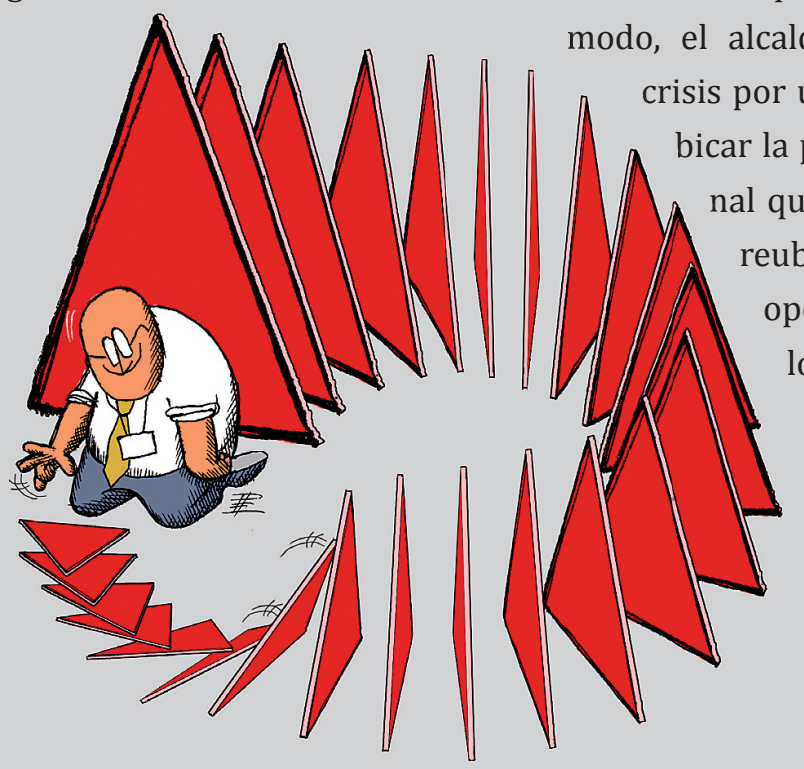

los clientes, si los competidores no están dispuestos a perderlos? La crisis no fue el incendio, sino la pérdida de ellos. Eso sí que puede liquidar el negocio. 


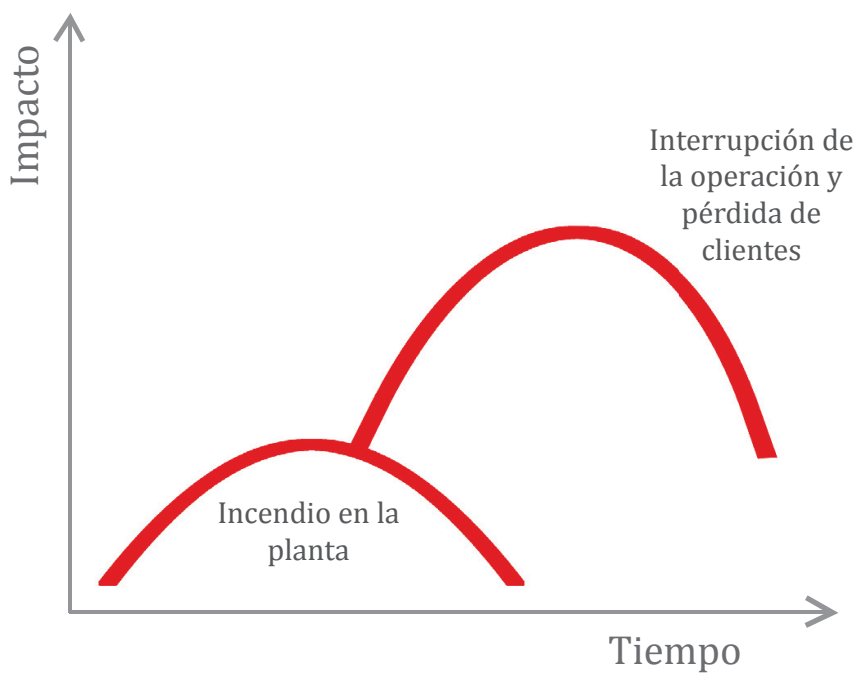

\section{Continuidad del negocio}

Preguntas que deben hacerse antes de experimentar un siniestro: ¿son los incendios temas previsibles que sabemos que pueden pasar a pesar de los sistemas de seguridad? Sí. Si la planta queda inoperativa por seis meses, ¿nos esperarán los clientes todo ese tiempo sin nuestro suministro? No. ¿Se irán con la competencia al día siguiente? Sí. ¿Podemos tener un acuerdo prenegociado con un fabricante (quizá del grupo u otro) que nos pueda fabricar por encargo o maquila con nuestra marca, especificaciones y volúmenes, de modo que se garantice el suministro a nuestros clientes en el plazo breve? Sí. ¿Es muy complicado? Si contamos con la suficiente antelación, no es muy complicado.

Pero si no se anticipó, al día siguiente del incendio usted debe tomar la guía telefónica y buscar a ese fabricante. Lo encontrará, pero estará a merced de este en la negociación. Quizá demore la manufactura o, lo que es peor, tal vez le agradezca el dato y después se entere de que él buscó a su cliente directamente.

Un aspecto más. Sin duda los llamados a responder al evento físico del incendio son las brigadas contra incendios de la empresa y las compañías de bomberos, hospitales y servicios de salud, y hasta Defensa Civil, si las proporciones alcanzan una mayor escala. Pero esos equipos no podrán lidiar con las 
consecuencias del incendio en los otros ámbitos, como la relación con los clientes, la continuidad del negocio, el manejo del flujo de caja positivo, etcétera. En otras palabras, la onda expansiva del incendio requiere decisiones de otro nivel. Hay una diferencia importante entre la emergencia y las consecuencias de esta en el negocio.

\section{¿Le falló el proveedor? ¡Tranquilo!}

Un contratista general que construye carreteras en las provincias alejadas de la capital posee varios campamentos a lo largo de la ruta. En uno de ellos, con 400 trabajadores, el proveedor de servicios de alimentación tiene un problema de liquidez por otros contratos, por lo que anuncia que enfrenta serias dificultades para operar y que en tres días dejará de hacerlo. ¿Cómo conseguir otro proveedor? No es difícil, quizá el segundo postor calificado del concurso esté dispuesto a hacerse cargo. Se le comunica esta necesidad y dice que con todo gusto lo hará, pero que le tomará un mes armar el servicio para asegurar los estándares de alimentación, sanidad e higiene de los alimentos. ¡Un mes! ¿Qué hará con los 27 días restantes?

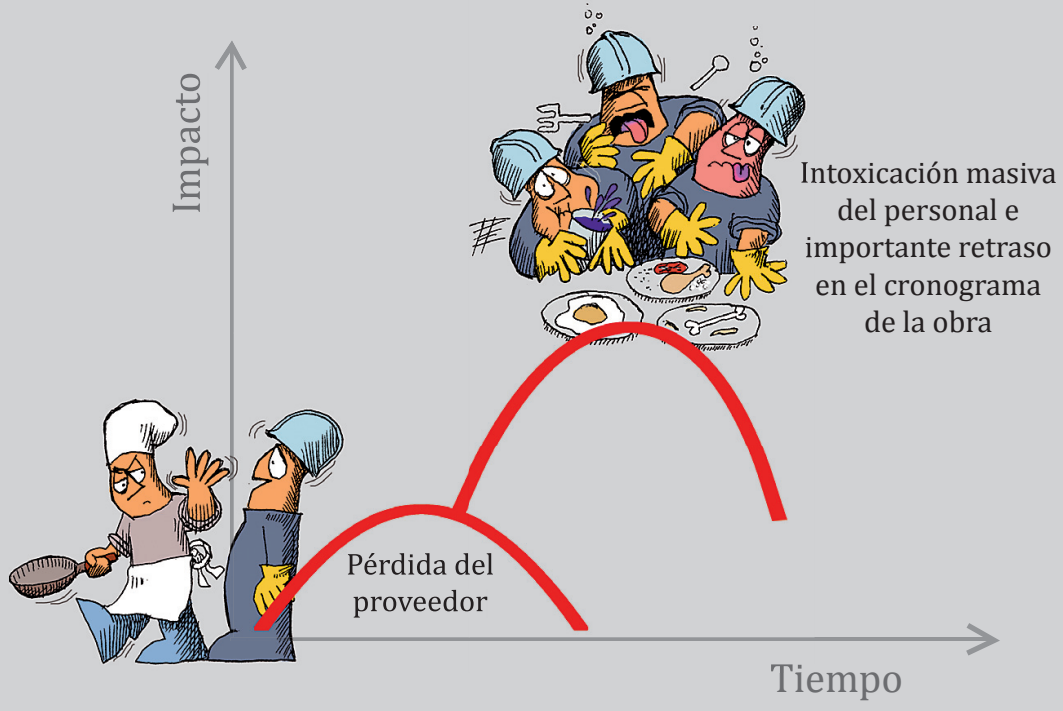


«Tranquilo, no hay problema», dice usted. Rápido, opta por el plan B: los restaurantes locales. Lamentablemente, ninguno puede proveer más de cincuenta menús al día y además desconoce sus condiciones de higiene. Los reúne, organiza, instruye, provee de utensilios, viste. Al cuarto día del servicio, un tercio de los trabajadores presenta síntomas de colitis severa, y una decena de ellos es trasladada de emergencia a Lima. Tiene que parar la obra. Crisis. Cuidado con que no venga otra detrás: familias de trabajadores afectados que denuncian ante la prensa que la empresa ha puesto en riesgo su salud con prácticas irresponsables en los servicios de alimentación. Lo más complicado: retrasos en el cronograma de ejecución de la obra, quejas del cliente, aplicación de penalidades, sobrecostos por tiempo de para con equipos y personal inactivo.

No hay que caer en la idea de que las crisis provienen necesariamente de accidentes en los que las personas y los equipos son los protagonistas. Muchísimas crisis provienen de aspectos no operativos. Los fraudes y las amenazas regulatorias bien pueden desencadenarlas. La aceleración que alcanza una crisis hoy puede sustentarse en la complejidad de los sistemas tecnológicos, financieros, comunicacionales, educativos o de entretenimiento. Todo está acoplado e interconectado. Los ámbitos de acción son muy amplios, y la visibilidad imposibilita que los problemas pasen desapercibidos. Los temas privados se vuelven de interés público.

\section{Un poco de diccionario}

Según el Diccionario de la lengua española, de la Real Academia Española3, 'crisis' es la situación de un «asunto o proceso cuando está en duda la continuación, modificación o cese, o momento decisivo de un negocio grave o de consecuencias importantes». Estos significados transmiten la principal característica de las crisis: la sensación de incertidumbre frente a cuestiones de gran trascendencia, determinantes de lo que venga, sea la continuación o la extinción. Es un 
momento en el que nosotros, otros o ambos determinaremos lo que ocurrirá. No se sabe cuál será la duración de ese momento, qué otras consecuencias negativas pueden aparecer, ni cómo resultará todo. Es lo impredecible e incierto lo que nos abruma, confunde y paraliza o nos hace sobrerreaccionar, complicando aun más las cosas. Crisis es ese punto de inflexión determinante para que la situación se agrave o se salve. Es ese instante especial en el cual lo que se haga o deje de hacer determinará la evolución de los hechos. Algunos esfuerzos por controlar la crisis pueden agravarla exponencialmente, mientras que simples acciones pueden tener la magia de contener el daño.

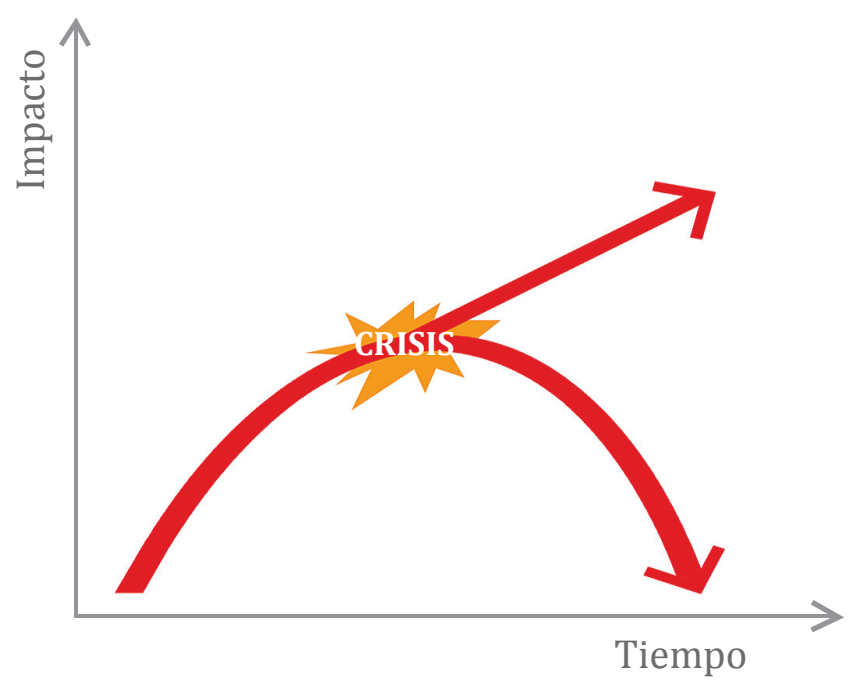

\section{Aceleradores y amortiguadores}

Una gripe común puede significar una semana de malestar para una persona relativamente sana, pero también la muerte para una persona enfermiza, crónicamente débil o desnutrida. Un sismo de intensidad media quizá no cause mucho daño, pero si todo el mes previo llovió copiosamente en la zona y saturó de agua el subsuelo, tendrá efectos mucho más fuertes, debido a la alteración de la estructura del suelo (expresado gráficamente, lo vuelve un flan). Los opositores a las actividades de las empresas extractivas pueden encontrar en un accidente relativamente menor la oportunidad perfecta para 
hacerse escuchar y movilizar a la población. Así como hay tazas de agua que no derraman la jarra, hay gotas que sí lo hacen. Usar términos en la empresa como «estamos en una semana sensible» 0 «tenemos las defensas bajas» da un sentido colectivo de alerta.

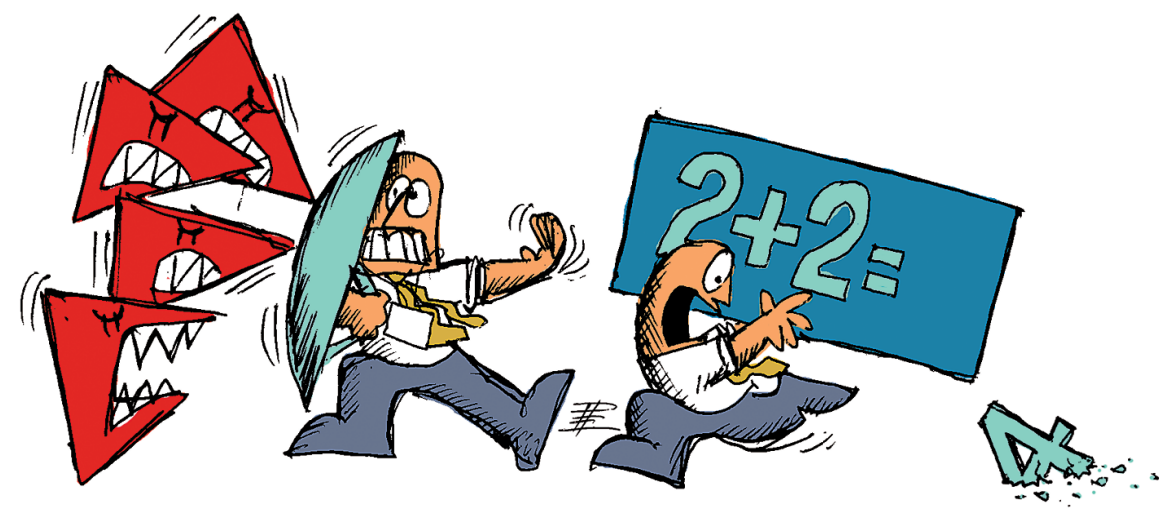

Existe una serie de elementos externos a la empresa que, conectados a las crisis, puede expandirlas, como las creencias, los temores, las posiciones, los intereses, las experiencias pasadas, las expectativas, las coaliciones, la cobertura mediática ${ }^{4}$.

Sin embargo, en lo que respecta a lo que su empresa puede hacer para expandir las crisis, el siguiente listado refleja los factores más frecuentes:

- Mentir.

- Ocultar información relevante.

- Culpar a otros cuando la culpa es de uno.

- Entrar en especulaciones.

- No asumir la responsabilidad cuando esta es obvia.

- Dejarse llevar por la ira o la arrogancia.

- Opinar prematuramente.

- Responder a evidencias sin contar con una base adecuada para hacerlo.

Yaziji identifica sectores que, de modo global, usualmente son particularmente propensos a situaciones de crisis; entre ellos figuran aquellos que:

- Ofrecen productos que presentan una salvación o una amenaza a la vida (empresas farmacéuticas o armamentistas).

- Confrontan costumbres sociales que están cambiando (moda, alcohol, tabaco).

- Producen importantes efectos colaterales (minería, manufactura pesada, procesamiento de basura).

- Disfrutan de un alto reconocimiento de marca (sectores de vestuario, alimentos y bebidas, automóviles).

- Se basan en nuevas tecnologías (ingeniería genética).

- Realizan negocios en distintas regiones con normas éticas y sociales diferentes (industria textil y de vestuario, petróleo y gas, forestal) (Cfr. Yaziji 2004: 4). 
- No informar apenas se cuente con información verificada.

- Responder: «Sin comentarios».

- Tomar distancia de las preocupaciones de las audiencias.

- Olvidar repetir los mensajes.

- No mantener comunicación con los empleados.

- Descartar apoyarse en recursos, experiencia y conocimiento externo.

- No transmitir una preocupación genuina.

- Mostrar incoherencia con los temas legales.

- Tomar decisiones sin pensar en las consecuencias.

- Rectificarse constantemente.

- Transmitir mensajes contradictorios.

- Poner los intereses económicos de la compañía en primer lugar.

Del mismo modo, hay factores que pueden más bien amortiguar las crisis, como un suceso aislado que tuvo rápida solución o la cobertura mesurada de los medios. Incluso la presencia simultánea de otra crisis de terceros actúa como amortiguador de la crisis que nos preocupa, pues llama la atención del público, que de otra manera estaría pendiente de nuestro caso. Las conocidas cortinas de humo van por ese lado.

Cada crisis viene rodeada de sus propios aceleradores y amortiguadores. Muchos dependerán de cuestiones que la empresa no puede dominar, pero varios otros sí serán susceptibles de ser controlados. En realidad, un plan de manejo de crisis es un amortiguador en la etapa aguda de ella. En plena crisis es fundamental identificar los aceleradores y contenerlos, a la vez que se detectan y fortalecen los amortiguadores. Sin duda, uno de los amortiguadores más eficaces es la reputación.

\section{Eventos e impactos no siempre van de la mano}

Precisamente, los aceleradores y amortiguadores determinan que los eventos y los impactos no estén proporcionalmente correlacionados. No porque el evento adverso sea leve, de modo necesario el impacto debe ser leve. Es perfectamente probable que un evento leve genere un grave impacto. 0 viceversa. Situaciones negativas extremas pueden determinar impactos graves o bien solo superficiales.

Hay personas que caen del quinto piso y fallecen en el acto, pero existen otras que salen casi ilesas. Otras se resbalan en la ducha y apenas se lesionan; algunas se matan. 
Los factores que determinan esta arbitrariedad de resultados provienen de amortiguadores y aceleradores. Muchas veces la suerte está presente, pero ella depende del azar y bien puede ser buena como mala. En todo caso, y como se dice frecuentemente, «la buena suerte hay que provocarla».

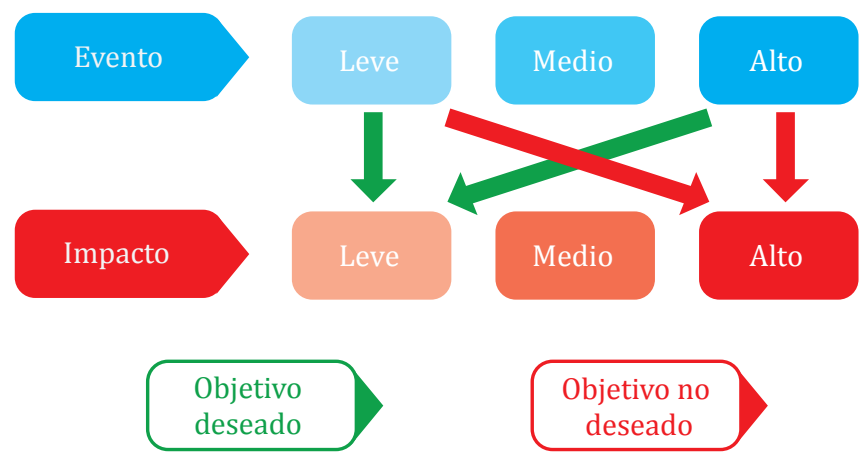

\section{A más impacto, menos control}

Algo paradójico ocurre en todas las crisis: las naturales, las corporativas, las políticas, las financieras o las personales. Es un factor estructural, sistémico, presente en cada una de ellas. Ninguna crisis escapa a la regla según la cual conforme se incrementa su nivel de impacto, se reduce la capacidad para controlarla.

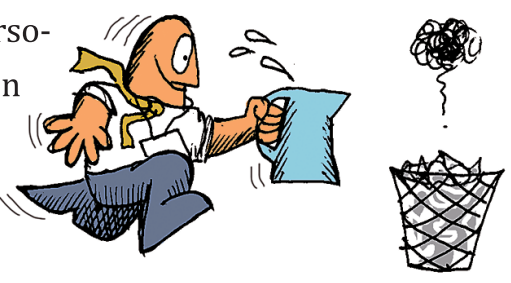

Una crisis enfrentada en su etapa temprana se resuelve de modo eficaz con relativamente poco esfuerzo y costo. Pero cuando estalla y despliega agresivamente su daño, las soluciones que antes eran eficaces dejan de serlo; habrá que recurrir a esfuerzos costosos y enormes, y aun ellos tendrán limitada eficacia. En otras palabras, las respuestas a la crisis en su etapa inicial (mejor aun, en la silente o cuando recién rompe la línea del síntoma) funcionan, tienen eficacia, pero a medida que la crisis aumenta en intensidad, esas mismas acciones se vuelven

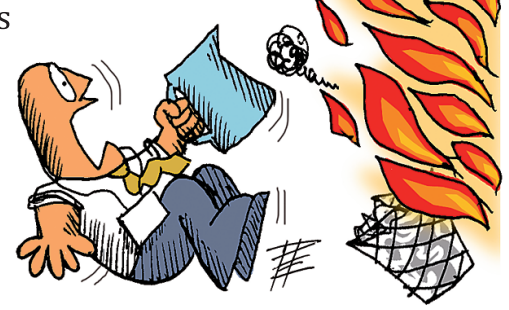
prácticamente estériles. 
Por eso, es mucho lo que se puede hacer en la etapa previa a la aparición o al estallido de la crisis; pero, cuando esta despliega su mayor daño, nada parece funcionar, y la experiencia demuestra que, de hecho, casi nada funciona. La capacidad de manejo se reduce drásticamente. La solución que hubiese funcionado en un principio ya no resulta eficaz. En el peor momento de la crisis es cuando menos se puede hacer.

Sin embargo, cuando la intensidad de la crisis amaina, las respuestas otra vez recuperan su eficacia. Cuando los ánimos se tranquilizan, los mensajes vuelven a ser escuchados, los espacios de diálogo y negociación se abren cuando poco antes era imposible plantearlos, los pacientes reaccionan mejor al tratamiento después de salir de la etapa crítica en la que se encontraban.

Gráficamente, la capacidad de respuesta o control a una crisis sigue una línea claramente inversa a su intensidad. Cuando la curva de impacto empieza a elevarse, decae la eficacia del esfuerzo de controlarla. Cuando esta línea de impacto decae, de manera automática se recupera la capacidad de manejo y control.

Así como las enfermedades se adquieren, incuban, entran en fase de clímax y después decaen, la capacidad para controlarlas es inversa a su intensidad. Las medicinas y los tratamientos funcionan cuando se está a tiempo; no sirven cuando es tarde. Precisamente es esta paradoja la que permite afirmar que una solución de regular calidad pero temprana es muchísimo más eficaz que una solución impecable pero tardía.

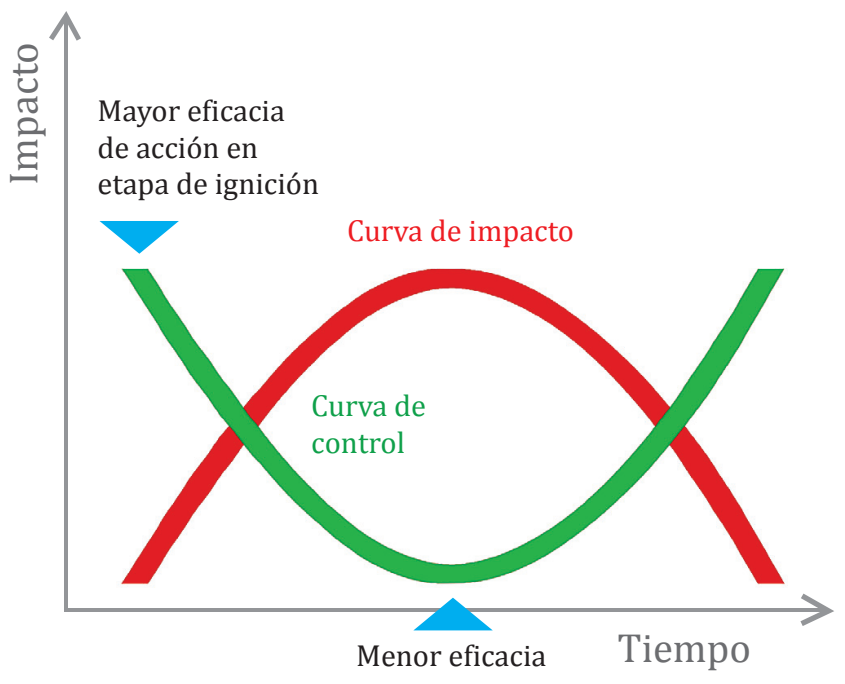

Fuente: Diermeier 2003: 186. 

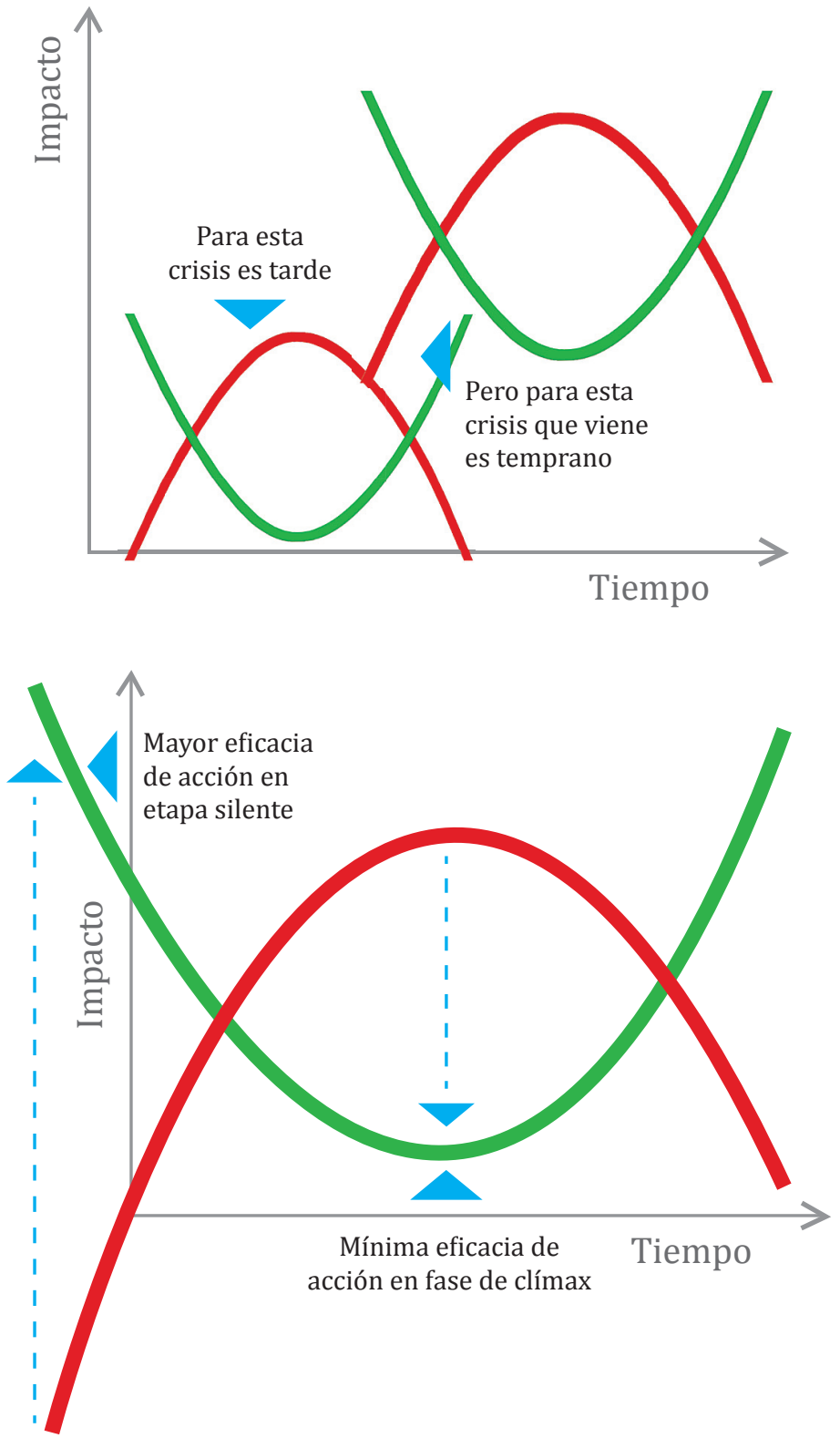


\section{Extintores, analgésicos, tratamiento y disculpas}

Un extintor funciona con eficacia cuando el fuego recién empieza, pero, cuando este cubre un área muy extensa, se vuelve prácticamente inútil.

Quien sufre de migraña sabe que, si toma dos analgésicos al primer síntoma, la dolencia podrá ser controlada, pero si no los tuvo a mano en ese preciso momento, treinta minutos después, en plena migraña, podrá tomarse dos analgésicos o veinte, y el efecto será el mismo: cero.

Un paciente de cáncer reaccionará más y mejor al tratamiento si la enfermedad es enfrentada tempranamente. No importa lo especializado, elaborado o costoso que sea el medicamento, si es aplicado en una fase muy avanzada (cuando el paciente no metaboliza, no tiene defensas, su capacidad de asimilación es muy limitada o su hemoglobina es baja), el efecto será mínimo o podría precipitar un desenlace fatal.

En lo peor de una discusión familiar, las explicaciones y hasta las disculpas que se ofrecen no siempre son escuchadas. Es más, hasta pueden tomarse a mal. La otra parte tendrá más apertura cuando los ánimos estén más tranquilos.

Si el incendio es controlado o no tiene más que quemar, si la migraña recorre su curva y entra en declinación, si el paciente de cáncer recupera capacidad metabólica y defensas, si la discusión cesó, cada una de las soluciones (el extintor, el analgésico, el medicamento y las disculpas) recupera su eficacia en lo que reste de la crisis.

Para un centro comercial cuyos vecinos no quieren más densidad o tráfico alrededor o para un puerto de gran escala que busca instalarse cerca de un balneario de verano, los esfuerzos de persuasión pueden tener éxito antes o después de la crisis, aunque muy difícilmente durante la etapa más álgida. ¿Será capaz el interesado de desplegar el proyecto de persuadir a una audiencia negativamente sensible - aunque no tenga esta la razón, pero igualmente cargada negativamente- de lo conveniente de la inversión sobre la base de argumentos técnicos de estudios de impacto vial o ambiental, llenos de gráficos sofisticados? Aunque suene costoso y afecte el valor presente neto de la inversión, quizá lo más recomendable sea hacer una pausa, esperar a que el tema se enfríe y recomponer su oferta y comunicación a estas audiencias. Ese sacrificio del cronograma (y del valor presente neto esperado) quizá sea menor comparado con la posibilidad de perder el proyecto. 


\section{Cultura organizacional procrisis: no reconocer, no priorizar, no actuar}

Según la experiencia, un factor sumamente importante asociado a la crisis es que, prácticamente siempre, alguna o buena parte de los equipos humanos de las empresas que la experimentaron sabían y estaban plenamente conscientes de que ella ya estaba en curso. Es cierto que hay crisis imposibles de prever y que escapan a cualquier modo razonable de anticipación, pero la estadística muestra que, en la gran mayoría de casos, las crisis se dieron aun cuando las empresas estaban absolutamente conscientes de que ocurrirían. A veces los mandos medios lo saben, y la alta dirección lo ignora. En otros casos, ambos lo saben. Sin embargo, no hubo anticipación, prevención ni preparación. ¿Qué pudo ocurrir?

La frecuencia con que esta situación se produce evidencia la presencia de patrones constantes: los equipos y los gerentes no reconocieron el problema, y si lo hicieron, no lo priorizaron; o incluso lo reconocieron y priorizaron, pero no se tomó ninguna acción al respecto.

No se reconocen las crisis cuando la gerencia no es informada o permanece indiferente ante el surgimiento de una amenaza o de un problema ${ }^{5}{ }^{6}$. No se prioriza cuando hay conciencia de las amenazas, pero no se consideran lo suficientemente graves como para prestarles atención inmediata ${ }^{7}$. No se actúa cuando, a pesar de que se reconocen las amenazas y se priorizan adecuadamente, no se toman decisiones o estas no son implementadas, o se responde parcialmente o con apreciaciones o supuestos

Cohn indica que las dificultades comienzan cuando un director general decide enterrar un problema, pues entonces se genera una bola de nieve. Recomienda reconocer que:

- Las malas noticias no se pueden esconder.

- Cuanto más rápida sea la respuesta, más rápido se disipa la historia.

- Se debe prestar atención a las señales de advertencia.

- La planificación de la crisis es una necesidad (Cfr. Cohn 2000: 10).

Watkins y Bazeman señalan que los errores de reconocimiento se cometen cuando los jefes permanecen indiferentes ante el surgimiento de una amenaza o de un problema, una falta de atención que puede afectar hasta a los mejores ejecutivos. Sin embargo, al examinar los desastres no previstos que afectan a las empresas, hemos descubierto que la gran mayoría de estos eran predecibles. La manera de determinar si hubo una falta de reconocimiento es evaluar si el líder de la organización dispuso de recursos para examinar el entorno en busca de posibles amenazas. Esto incluye averiguar si analizó e interpretó la información razonablemente bien. En caso contrario, el líder debe asumir su responsabilidad (Cfr. Watkins y Bazeman 2002: 4).

Según Watkins y Bazeman, los errores de priorización surgen cuando los líderes reconocen las posibles amenazas, pero no las consideran lo suficientemente graves como para prestarles atención inmediata. Las sorpresas predecibles también se producen cuando, aunque se reconozca una amenaza, no se le otorga importancia. Los errores al establecer prioridades son muy comunes, ya que normalmente los líderes de organizaciones son asediados por múltiples factores de atención. ¿Cómo pueden distinguir entre una sorpresa que sí se producirá y el montón de posibles sorpresas que no lo harán? La respuesta es que no se puede hacer esa distinción con un ciento por ciento de precisión (Cfr. Watkins y Bazeman 2002: 4). 
incorrectos ${ }^{8}$. El constante escaneo (como un radar que se extiende más allá del campo visual) de las condiciones de riesgo internas y externas es una de las prácticas más saludables que pueden recomendarse, siempre y cuando esté acompañada de una efectiva movilización para enfrentarlas.

\section{¿Por qué no reconocemos la inminencia de una crisis?}

Varias pueden ser las explicaciones de estos patrones, desde sensación de invulnerabilidad, responsabilidad diluida, bloqueos de comunicación o información fragmentada en compartimientos estancos hasta miedo a informar lo que está pasando. La dimensión del comportamiento organizacional en que se mezclan la psicología individual y la grupal, el manejo de las emociones, los intereses individuales y colectivos, y hasta el clima laboral, son un factor determinante en este campo.

Estas situaciones pueden estar presentes en todos los niveles jerárquicos de la empresa, pero son letales cuando se instalan en la percepción y la conducta de los líderes; es decir, en los cargos gerenciales y de decisión, pues se contagian a todos los empleados de la organización. Hay quienes consideran que cuando el salario de uno depende de no hacer las preguntas incómodas a sus jefes, quizá uno nunca las haga. A lo más, comentará los temas confidencialmente en el pasillo con un colega, pero no en el comité de gerencia. Algunos de estos patrones pueden manifestarse de las siguientes maneras:

Señales ignoradas. Todas las crisis vienen anunciadas, muchas veces con larga anticipación. La etapa silente siempre viene acompañada de señales que la van anunciando. Los primeros en advertirlas son los empleados, pues están cerca del problema. Sin embargo, es probable que no avisen porque creen que pueden resolverlo ellos mismos (sobreestimando sus capacidades o subestimando el problema), o sienten que avisar es sinónimo de pedir ayuda y, por tanto, de declararse incapaces de resolverlo por sí mismos; incluso, son testigos de cómo se maltrata al que avisa. Los jefes intolerantes despluman

Para Watkins y Bazeman, la falta de movilización se produce cuando los líderes reconocen y dan la prioridad adecuada a un problema nuevo, pero responden de manera ineficaz. Cuando se considera que una amenaza es seria, el líder está obligado a movilizarse para intentar impedirla. Si toma medidas preventivas acordes con los riesgos, no debe ser considerado responsable. Tampoco debe ser culpado si no contaba con los recursos para responder con eficacia (Cfr. Watkins y Bazeman 2002: 5). 
literalmente a las palomas mensajeras de malas noticias ${ }^{9}$. La mina San José, en Chile, que en 2010 sepultó a 33 trabajadores, venía de varios procesos de sanciones y amenazas de cierre precisamente derivadas de las condiciones de inseguridad que reportaba con frecuencia. La torre de petróleo de British Petroleum en el golfo de México había dado varias señales de fallas antes de su colapso y del peor derrame conocido en la historia.

Negación. La afirmación «ese problema no lo tenemos acá» es una frase demasiado utilizada cuando se está en la etapa silente, e incluso en fases mucho más avanzadas. La actitud del avestruz que entierra la cabeza ante los problemas es un rasgo determinante para aumentar el impacto de la crisis, pues no solo desaprovecha la posibilidad de una respuesta temprana, sino que contribuye de forma significativa a empeorar la percepción de la opinión pública, que no justifica la tardanza de la respuesta ${ }^{10}$.

Subestimación. Es el típico «eso no nos pasará a nosotros». Por algunas razones propias del campo de la psicología, los individuos y los grupos tienden a asignar un valor muy bajo a las posibilidades de daños por hechos propios o de terceros. Muchas veces, la concentración en las actividades y los objetivos propios de la empresa no dan tiempo de pensar en escenarios o situaciones más bien adversas. Los grupos prefieren discutir y abordar los temas de crecimiento, posicionamiento o consecución de objetivos. Detener esa maquinaria de pensamiento y energía para analizar qué podría ocurrir mal es para muchos o una pérdida de tiempo o, peor aun, una actitud poco consecuente con la empresa. Los pájaros de mal agüero traen mala suerte ${ }^{11}$. También hay el «eso nos ha pasado antes y, la verdad, no fue tan terrible», o el «eran otras épocas».

Cohn alude a que los estudios muestran que el $80 \%$ de desastres potenciales los generan las personas y pueden ser prevenidos. Con pocas excepciones, los problemas causados por ellos dejan un rastro de tempranas señales de advertencia mucho antes de que la crisis real explote. El mismo autor se refiere a una investigación del Instituto de Estudio de Gestión de Crisis, que reveló que el 68 \% de las crisis de negocios son creadas por la dirección, y solo el $19 \%$ por los empleados (Cfr. Cohn 2000: 11). o no. Su preocupación deberá centrarse en qué clase de crisis experimentará, qué forma tomará, y cómo y cuándo sucederá. Señala que el principal enemigo (o la principal barrera por superar) es la negación. El cliché «eso no nos puede pasar; por lo tanto, no necesitamos gastar dinero para estar preparados en caso de la crisis» es letal. Las crisis causadas por el hombre se pueden evitar siempre y cuando se examinen las diversas formas de detección de señales gracias a la constante observación del entorno (Cfr. Mitroff y Anagnos 2001: 8).

11 Cohn plantea que el peor modo de entrar en el problema es fingir que este no existe. El intento de hacer creer a la opinión pública que no hay tal evento negativo no solo inmoviliza a la empresa frente a él, sino que retrasa la respuesta y daña seriamente su imagen. Solo se conseguirá que los directivos se conviertan en los puntos de broma de los programas de televisión nocturnos. Así que dé la bienvenida al primer pecado mortal para afrontar una crisis, decir: «Eso nunca pasará aquí». Este es el mantra del directivo ignorante. Los resultados son dolorosos (Cfr. Cohn 2000: 3). 


\section{Francia y la Línea Maginot}

Los franceses, después de su terrible experiencia en los duros combates de trinchera contra los alemanes durante la Primera Guerra Mundial, construyeron la famosa Línea Maginot. Más de 450 kilómetros de túneles y fortificaciones estratégicamente colocados en la frontera serían la gran defensa para el futuro y la garantía de la seguridad. Cuando estalló la Segunda Guerra Mundial, los alemanes simplemente ignoraron la línea e invadieron Francia a través de Bélgica, en pocos días y sin mayor esfuerzo. El concepto de la guerra había cambiado: ya no era el de trincheras y de terreno ganado palmo a palmo, con lentos avances de tropas movilizadas a pie o artillería tirada por caballos, sino el de la rápida movilización con apoyo de camiones, tanques y aviones. En realidad, la Línea Maginot no falló. Falló la «mentalidad Maginot»: lo que antes servía no sirve ahora.

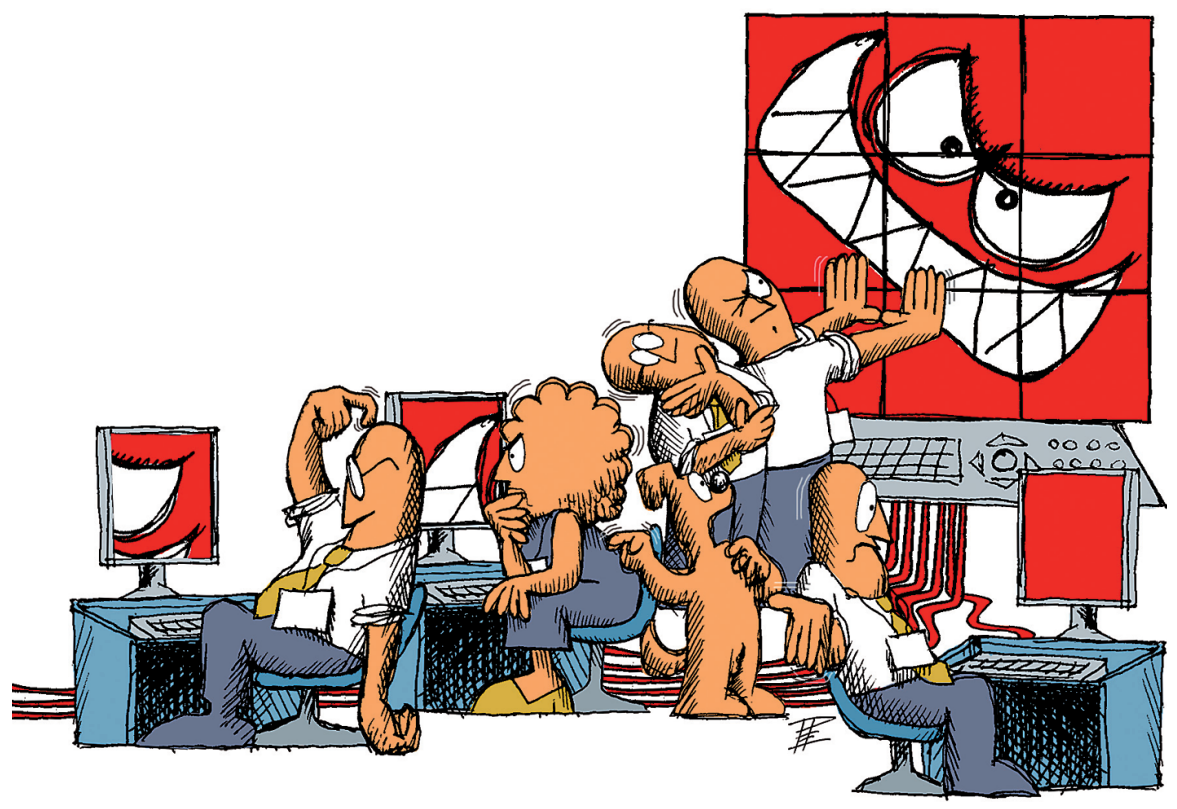

Información desintegrada y responsabilidad diluida. La información que da cuenta de una crisis real o potencial puede estar completa, pero no siempre integrada. Es pro- 
bable que esté fragmentada en diversas áreas de la empresa, de manera tal que no revele su potencial negativo. Nadie tiene el rompecabezas completo. Nadie ve la gran foto. En la ausencia de un mecanismo que agrupe y sistematice esta información, probablemente no se adviertan las señales del peligro que se acerca.

Los responsables de que ello no ocurra pertenecen a la más alta jerarquía. Es una tarea de jefes, no de subordinados. Los primeros tienen la responsabilidad de dedicar todo su tiempo, energía, liderazgo y compromiso a trabajar en equipo con el propósito de resolver el problema; los mandos medios poseen una capacidad de decisión y de acción limitada, carecen de la visión de sus superiores y podrían estar más interesados en proteger sus puestos que en proteger la empresa ${ }^{12}$.

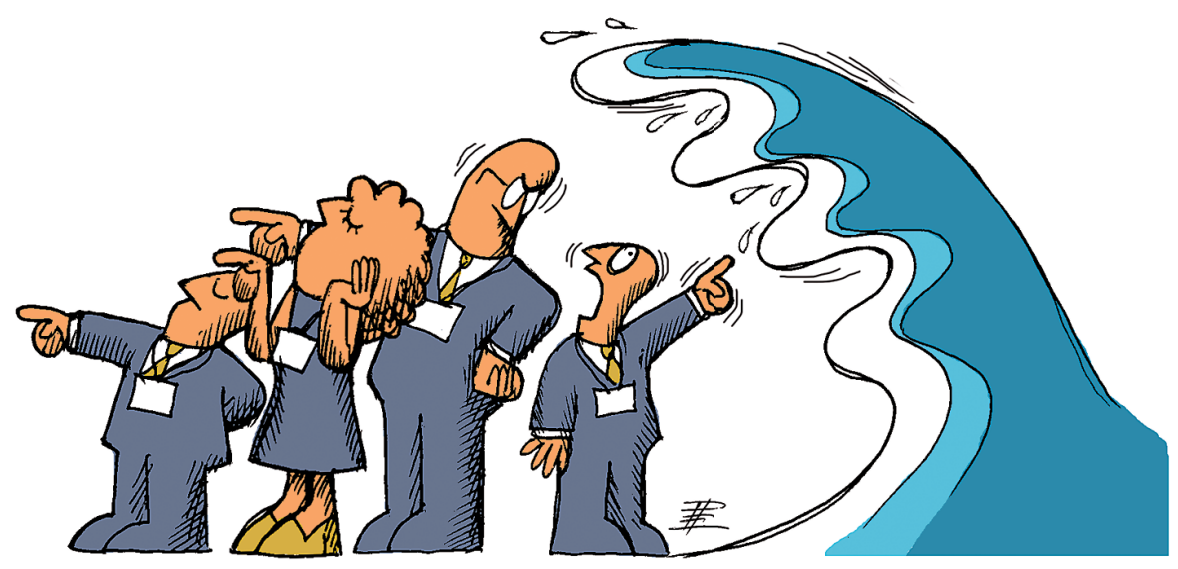

Para Watkins y Bazeman, la vulnerabilidad organizacional se asocia a la estructura misma de las organizaciones empresariales (especialmente cuando son grandes y complejas) y dificulta anticiparse a las sorpresas predecibles. Debido a que las empresas están generalmente divididas en silos organizacionales, la información que el líder necesita para ver y evaluar una amenaza que se aproxima es muchas veces fragmentada. Diferentes personas tienen distintas piezas del rompecabezas, pero nadie tiene todas. En teoría, la dirección corporativa debería ejercer una función de síntesis y reunir la información fragmentada para ver el cuadro completo.

Sin embargo, los obstáculos para aquellos que toman decisiones a un nivel mayor son grandes. La información es filtrada a medida que asciende en la escala jerárquica; la información delicada o molesta es retenida o encubierta y quienes están en la cima inevitablemente reciben datos incompletos o distorsionados. Los silos organizacionales no solo dispersan la información, sino también la responsabilidad. A veces, todos suponen que otra persona está asumiéndola y entonces nadie actúa. Otras veces, se le asigna demasiada responsabilidad a una parte de la organización ante un determinado problema. Otras partes de la organización, entre las que se encuentran aquellas que cuentan con información o enfoques importantes, no son consultadas e incluso son excluidas deliberadamente del proceso de toma de decisiones. ¿Cuál es el resultado? El tema se analiza desde una perspectiva demasiado limitada y los problemas potenciales no son reconocidos o no se les da la debida prioridad (Cfr. Watkins y Bazeman 2002: 7). 
Pensamiento «melcocha». Esta es una denominación tomada por Roberto Lerner ${ }^{13}$ para definir el concepto americano de groupthink o «pensamiento demasiado homogéneo». Alude a la circunstancia en que las organizaciones tienen una mística cohesiva que presiona hacia la unanimidad de las decisiones y sepulta el análisis de otras opciones. En realidad, el grupo tiende a pensar igual y se muestra agresivo o intolerante con quien lo haga de manera diferente. Es frecuente ver a estos grupos caer en la ilusión de invulnerabilidad, optimismo exagerado, toma de riesgos extremos, minimización de las señales contrarias, etiquetado arbitrario de interlocutores ${ }^{14 / 15}$.

\section{Un nuevo comienzo para Volkswagen}

La compañía alemana está enfrentando probablemente uno de los mayores escándalos en su historia, Las consecuencias de la crisis les han costado caro, ya que en solo unas cuantas horas el valor de Volkswagen en la bolsa descendió en 15600 millones de dólares. Las investigaciones señalan que Volkswagen ha estado manipulando durante siete años las pruebas para las emisiones contaminantes de sus coches diésel en los Estados Unidos. Concretamente, la empresa

Cfr. Lerner 2003.

Watkins y Bazeman sostienen que la vulnerabilidad organizacional es generalmente la más difícil de sobrellevar; aunque rara vez se pueden superar todas las barreras internas de una organización, sí resulta posible contrarrestar sus efectossiseponen en práctica sistemas para recolectar información sensibleque cruce toda la empresa. Para esto se requiere que los líderes formen uno o más equipos multifuncionales, encargados de reunir y sintetizar la información útil desde todos los rincones posibles de la empresa (Cfr. Watkins y Bazeman 2002: 7).

Watkins y Bazeman denominan «vulnerabilidad psicológica» a los defectos cognitivos que hacen que una persona no vea que se aproxima una amenaza. La mente humana es un instrumento notoriamente imperfecto. La investigación acumulada ha demostrado que la manera como procesamos la información adolece de muchos defectos, que pueden llevarnos a ignorar o a subestimar un desastre que se aproxima. Estos son algunos de los más comunes:

- Tendemos a ilusionarnos y a pensar que las cosas son mejores a como verdaderamente son.

- Damos gran importancia a los hechos que respaldan nuestras ideas preconcebidas y desestimamos la evidencia que las pone en tela de juicio.

- Prestamos muy poca atención a lo que otras personas hacen. Pasamos por alto, en consecuencia, nuestra vulnerabilidad ante las sorpresas predecibles causadas por las decisiones y acciones de los demás.

- Pertenecemos al presente. Tratamos de mantener el statu quo y le restamos importancia al futuro.

- La mayoría de nosotros no nos sentimos impulsados a prevenir un problema que no nos ha afectado personalmente. Solo actuamos después de haber sufrido un daño significativo o después de poder imaginarnos gráficamente el peligro (Cfr. Watkins y Bazeman 2002: 5). 
diseñó un software fraudulento que permitía a los autos identificar cuándo se estaban midiendo las emisiones de los vehículos, para alterar así sus resultados. Entre los años 2009 y 2015, la compañía instaló este software en 11 millones de vehículos de las marcas Volkswagen y Audi comercializados alrededor del mundo. La renuncia del presidente ejecutivo de la empresa no se hizo esperar. "Estoy en shock por los eventos de los últimos días. Volkswagen necesita un nuevo comienzo", señaló al dejar el puesto.

Yo oculto. Muchísimas crisis vienen del llamado «yo oculto» de las organizaciones. Se refiere a la existencia de algún factor sumamente negativo en la empresa, conocido por esta pero desconocido para los demás. He aquí cuando se enfrenta el apasionante dilema de la transparencia (disclosure): o nos anticipamos y reconocemos el problema públicamente o nos la jugamos y confiamos en que nadie se enterará ${ }^{16}$.

16 Gonzalo Galdos reseña con habilidad toda una colección de distorsiones en la toma de decisiones en los equipos gerenciales, como la adicción al corto plazo, la manía de postergar lo estructural, la dictadura de los persuasivos, la navaja de Occam, el palco de los Muppets, el sendero del miedo, el sesgo de confirmación, la trampa del anclaje, la maldición del ganador, el efecto conformismo, la escalada del compromiso, las metas a la deriva, o muchos dueños o ninguno, entre otros (Cfr. Galdos 2015). 


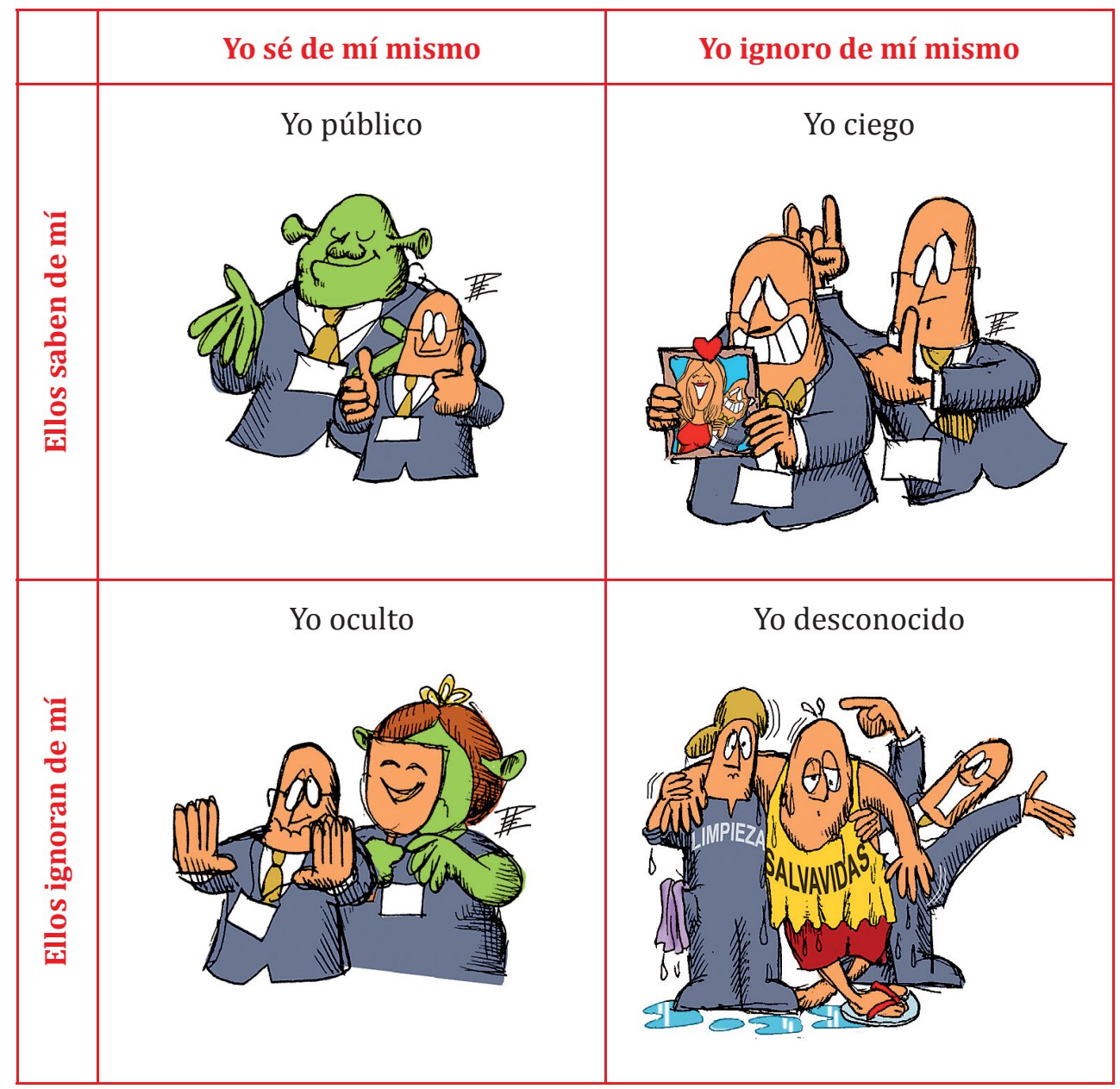

Fuente: Ventana de Johari (Joseph Luft y Harry Ingham), tomada de Mitroff y Anagnos 2001: 64. 


\section{Dilema de transparencia}

\begin{tabular}{|c|l|l|}
\hline & \multicolumn{1}{|c|}{$\begin{array}{c}\text { Nadie sabe } \\
\text { mi problema }\end{array}$} & \multicolumn{1}{|c|}{$\begin{array}{c}\text { Todos saben } \\
\text { mi problema }\end{array}$} \\
\hline ¿Lo digo? & $\begin{array}{l}\text { Me adelanto } \\
\text { y lo cuento }\end{array}$ & $\begin{array}{l}\text { Forzado a contar } \\
\text { la verdad }\end{array}$ \\
\hline ¿Lo oculto? & Me callo y me la juego & Hermetismo \\
\hline
\end{tabular}

Fuente: Mitroff y Anagnos 2001: 68.

\section{Desalineamientos costosos}

Analizando muchos casos de crisis, es posible comprobar que muy frecuentemente las crisis escalan a niveles casi inmanejables debido a la ausencia de alineamiento entre factores que necesariamente deben combinarse y operar recíprocamente.

No es difícil imaginar cuáles podrían ser estos: uno de los más usuales es la contradicción entre lo que se dice y lo que se hace. Típicamente, cuando ante una imputación de fraude el involucrado sostiene públicamente que nada tiene que ocultar y que ofrecerá toda su cooperación ante la justicia, pero simultáneamente usa todos los recursos judiciales de carácter procesal para evitar justamente enfrentar la corte. 0 cuando se proclama a la prensa que se hará todo lo posible por los afectados pero el apoyo real a estos es inexistente.

Otro desalineamiento crítico frecuente está referido a planes o protocolos de manejo de crisis y los equipos humanos encargados de implementarlos. Los primeros pueden ser buenos, rigurosos, precisos, o todo lo contrario; incluso inexistentes. De otro lado, los equipos que enfrentarán las crisis pueden tener carácter y temple para abordar una crisis, o carecer de él. Es decir, pueden mostrar alta energía y disposición para tomar acción y no correrles al problema o, por el contrario, ser pusilánimes, temerosos y orientados a evadirlo. 
Tanto los planes o protocolos como el carácter de los equipos son claves para contener una crisis, de modo tal que hay que preocuparse mucho en desarrollar ambos ámbitos. Una buena manera de entender lo que resulta de un desbalance entre estos es analizando el siguiente cuadro:

\begin{tabular}{|c|c|l|l|}
\hline \multicolumn{2}{|c|}{ Plan o protocolo de manejo de crisis } \\
\hline \multirow{2}{*}{$\begin{array}{c}\text { Energía del } \\
\text { equipo }\end{array}$} & Alta & Inexistente & \multicolumn{1}{c|}{ Bueno } \\
\cline { 2 - 4 } & Baja & $\begin{array}{l}\text { Esto es problema } \\
\text { del jefe }\end{array}$ & $\begin{array}{l}\text { ¿Cómo hago para evadirme } \\
\text { de la responsabilidad? }\end{array}$ \\
\hline
\end{tabular}

\section{ENFRENTAR LAS CRISIS}

\section{El objetivo 1 en una crisis: la contención}

El objetivo más importante en una crisis es su contención: evitar que siga haciendo daño, impedir el incremento progresivo de su impacto, cortar la posibilidad de que migre a una categoría superior, apagar el incendio, cortar la fuga de petróleo, impedir el retiro masivo de fondos, atender a los heridos para evitar su fallecimiento, detener la extensión y profundización del problema en el espacio y el tiempo, controlar los daños (el llamado damage control).

La dificultad principal de la contención es que precisa una clara identificación del problema, lo que exige información pertinente y válida sobre su calibre. Puede que en el momento de la crisis no tenga ninguna o solo reciba algunas pocas piezas del rompecabezas; o, lo que es peor, reciba miles de piezas, no solo desordenadas sino mezcladas con piezas de otros juegos de rompecabezas que no tienen nada que ver con el juego actual y que provienen del rumor o de la especulación. Distraen, confunden y quitan tiempo y concentración. Decidir con poca información es adivinar. Es jugar a los dados. Con ello, lejos de contener la crisis, se expandirá. 
Para poder revisar todo el contenido de esta edición, visite nuestra tienda virtual.

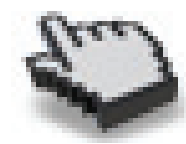

\section{Manejo de crisis} ¿Qué hacer el dia en que todo está en contra nuestra?

Segunda edición

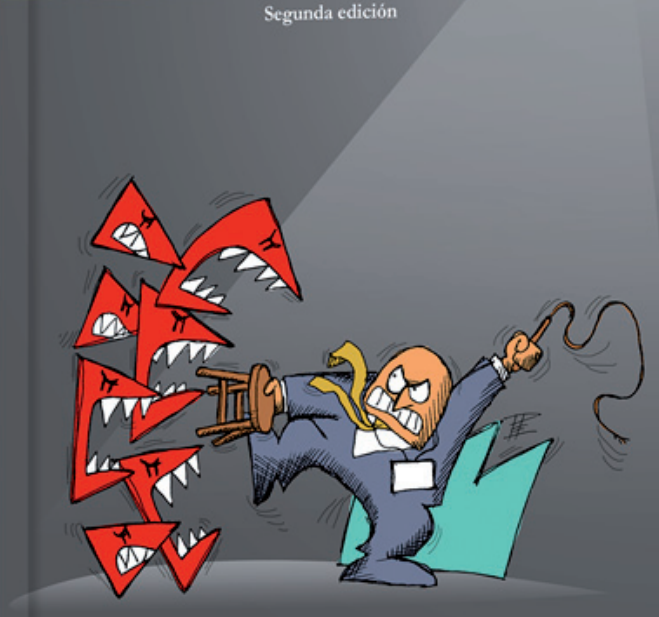

